\title{
GIRL CHILD RIGHTS: A COMPARATIVE STUDY BETWEEN INTERNATIONAL CONVENTIONS AND IRAQI LAW
}

http://dx.doi.org/10.47832/2757-5403.4-3.28

Hiba Thamer Mahmood AL-SAMAK 1

\begin{abstract}
:
Girls still suffer from violations for their rights, they are the first victims for violation of human right. pay attention to girls and terminate the matter of the discrimination against them, especially in the developing countries and build their personality to be themselves and their families able to face the future and to be pioneers influence the society, Therefore, the United Nations focused on the rights of girls and promised it one of the sustainable development goals that it seeks to achieve in 2030. However, we lack legislation and international conventions on the rights of the girl child, Convention on the Rights of the Child for 1989, and Convention on the Elimination of All Forms of Discrimination Against Women (CEDAW) 1979 violation against them are considered the keystone of the rights of girls internationally.

I shall use the comparative approach in my research methodology between the Iraqi law and the international conventions and agreements, in order to compare the general provisions, as well as mentioning the most serious violations of the rights of the girl child in Iraqi society and the provisions of Islamic Sharia regarding these violations. The study aims to find special rules for the girl child that distinguish her and grant her adequate rights from childhood, as I did not find anyone who addressed the rights of the girl child in Iraqi Republic in the light of international law, despite the serious violations of her rights, and we did not find the Iraqi legislator has sought or seek to develop legislations that limiting these violations.

Thus, I shall search the problem in two researches, the first about what are the rights of the girl child, The second research is about the main rights of girls. The most important results I found that the rights of the girl child encouraged and helped girls to develop mentally, physically and psychologically, that contribute to the development of societies, and the most underdeveloped states are those that do not consider or pay attention to the rights of girls under the age of eighteen, With the need to pay attention to the education and upbringing of girls to be a leading woman in society and to be able to live and provide for her family.
\end{abstract}

Key words: Girls, Human Right, Iraqi Law, International Conventions.

\footnotetext{
${ }^{1}$ Dr. , Baghdad University, Iraq, hiba.t@colaw.uobaghdad.edu.iq, https://orcid.org/0000-0002-2789-2956
}

Copyright $(\mathcal{C}$ Published by IJHER Journal, www.ijherjournal.com Rimar Academy, Fatih, Istanbul, 34093 Turkey

All rights reserved 


\title{
حقوق الطقلة: دراسة مقارنة بين الاتفاقيات الدولية والقانون العراقي
}

\author{
هبة ثامر محمود
}

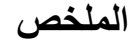

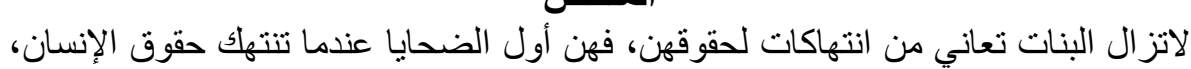

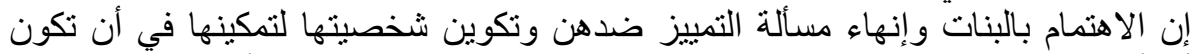

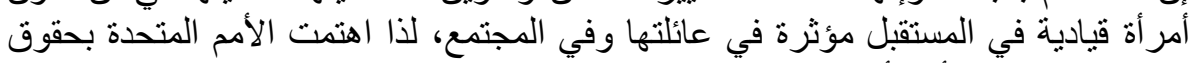

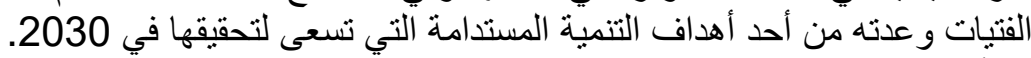

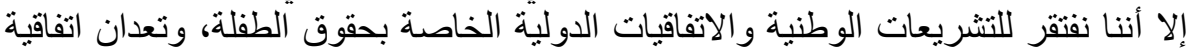

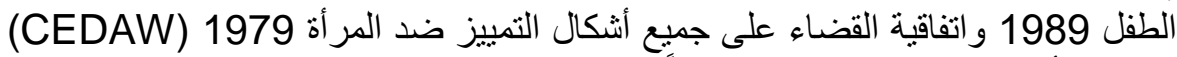
الحجر الأساسي في حقوف الفتيات دولياً.

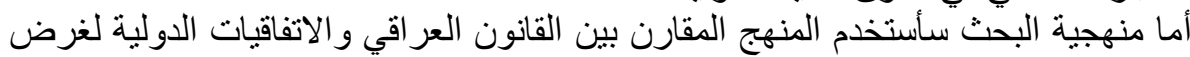

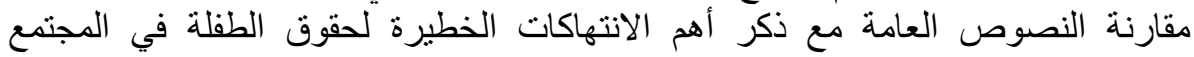
العر اقي وموقف الشريعة الإسلامية من هذه النته التهاكات.

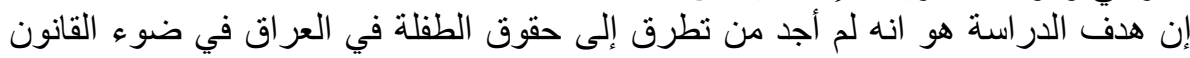

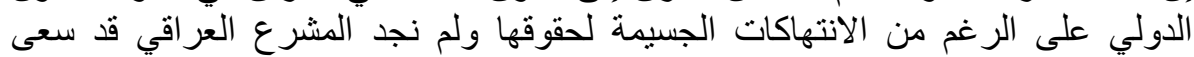
لوضع تشريعات تحد من هذه الانتهاكات.

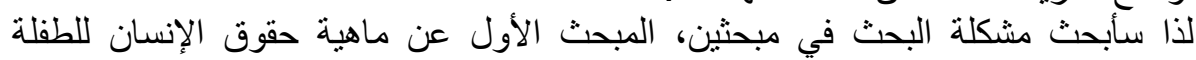
وبحثت في المبحث الثاني في حقوق الطمث في الطفلة الأساسية.

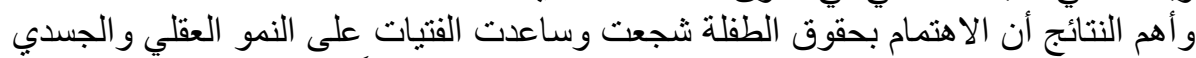

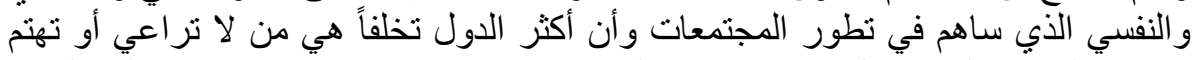

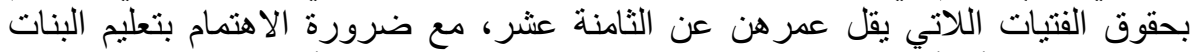

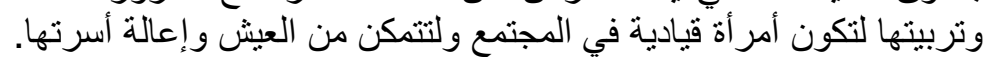

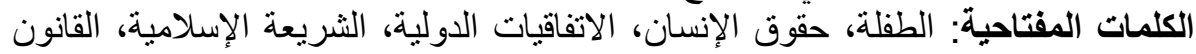

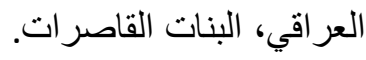

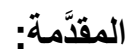

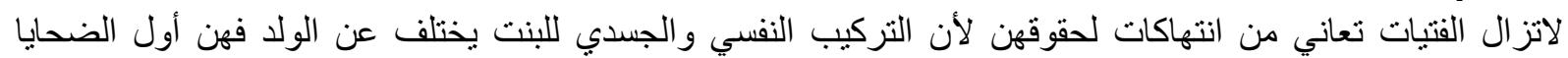

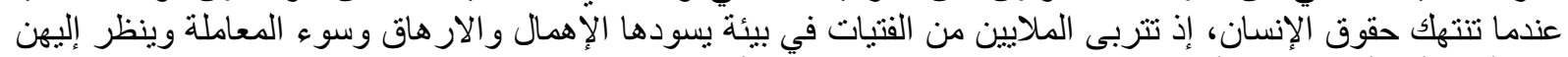

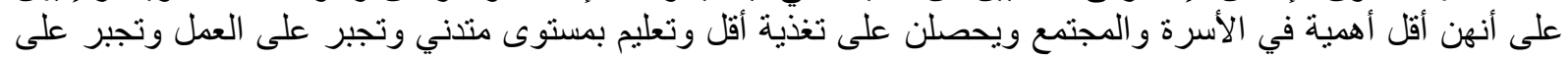

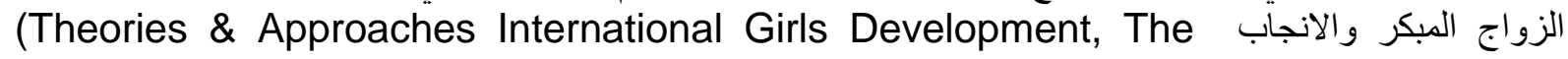
بesource Center for Adolescent Pregnancy Prevention (ReCAPP), 1995)

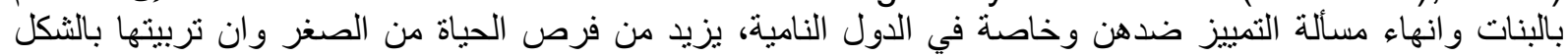

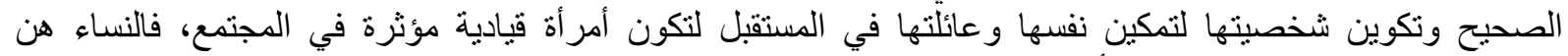

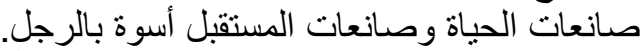

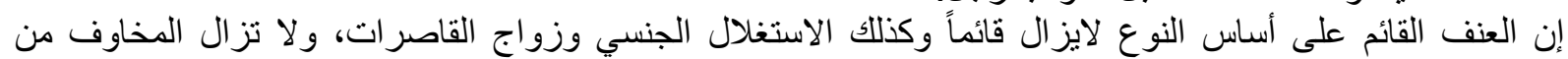
الوصم بالعار من جرائم الثرف وغير ها عقبات حقيقية امام تحقيق العدالة للناجيات من العنف القائم العائم على النوع (اليونسيف

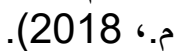

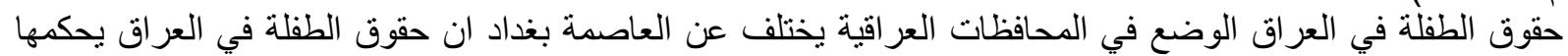

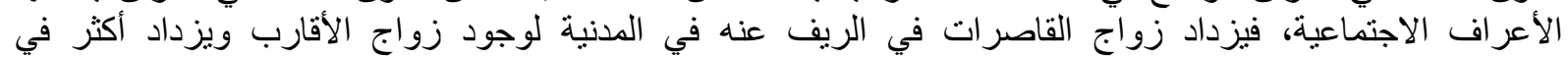

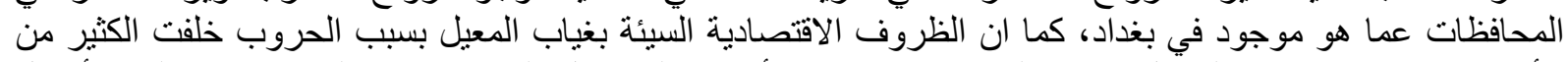

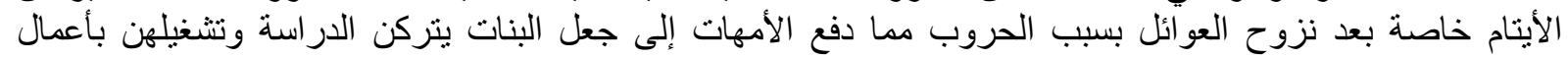




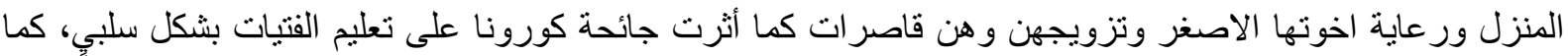

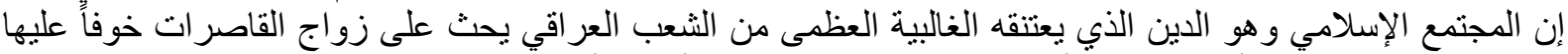

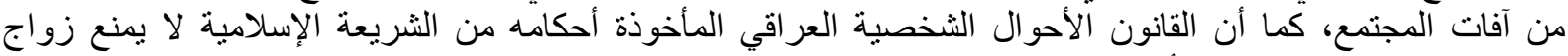

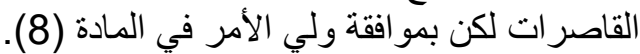

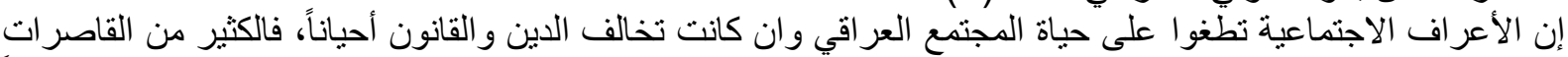

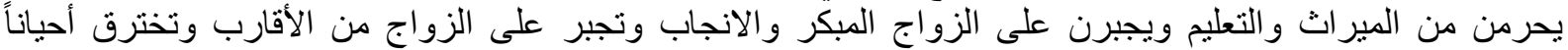

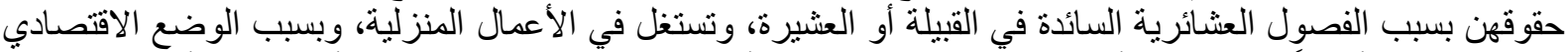

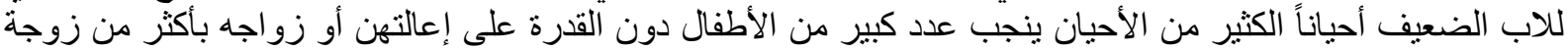

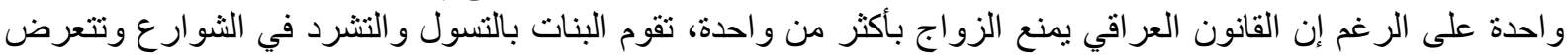

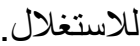

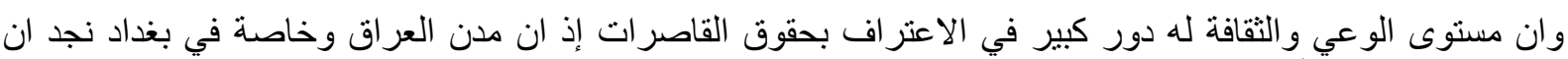

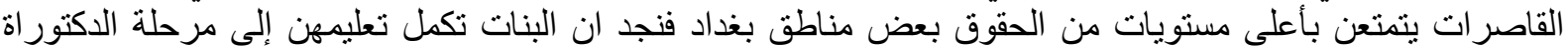

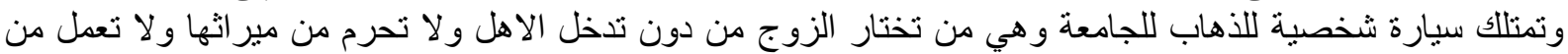

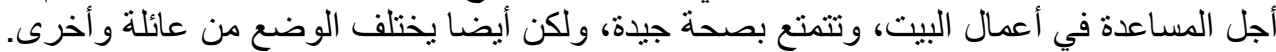

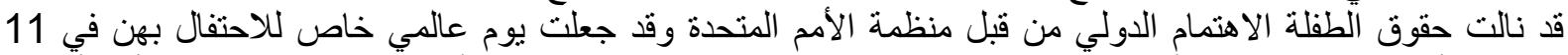

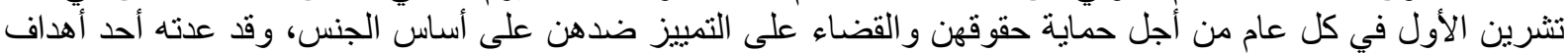

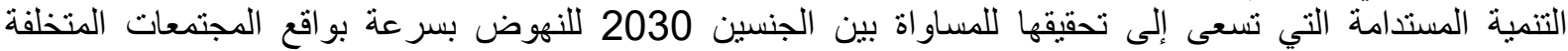

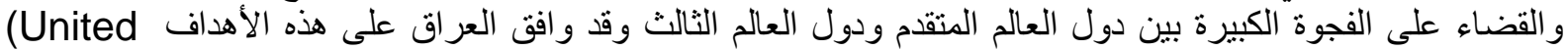

.Nation, 2020) وقد أكد الإسلام على مكانة البنات وأهمية تربيتهن وأهمية عطائهن حقوقهن وحرم التمبيز ضدها، إذ خلق اله الذكر

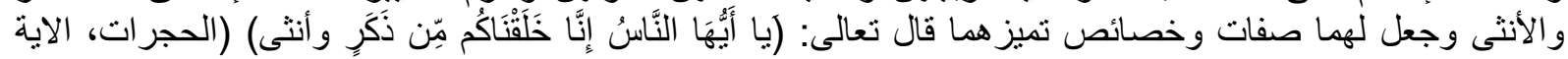

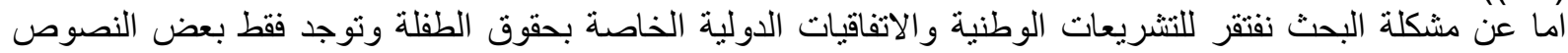

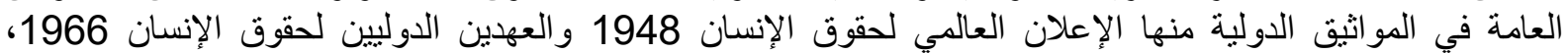

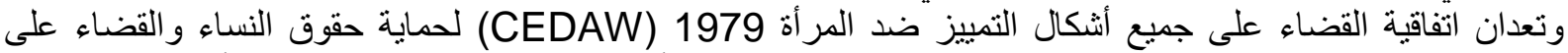

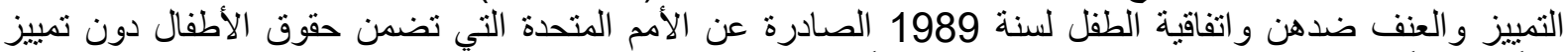

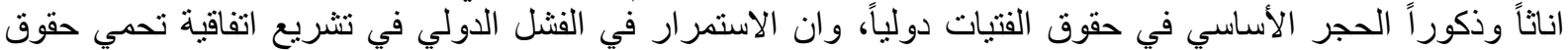

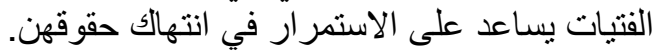
أما عن الهدف من البحث هو النه لم يسبق ان تم بحث حقوق الطفلة في العراق على الرغ فم من الانتهاكات الكبيرة لحقوقهن

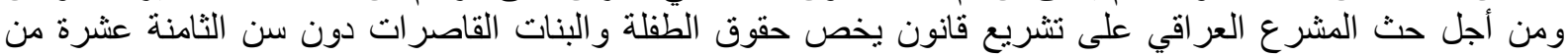

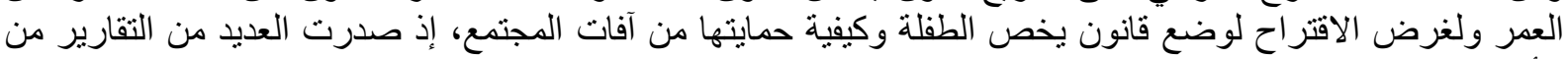

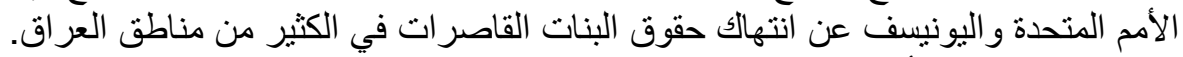

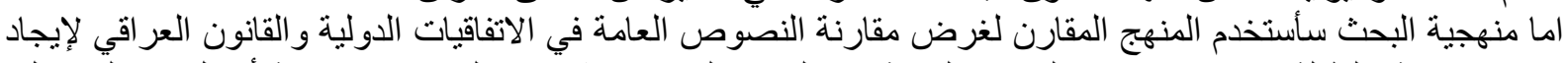

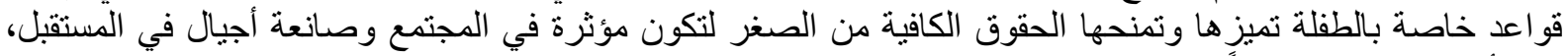

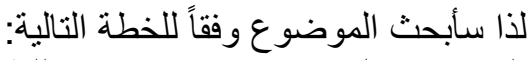
المبحث الاول: ماهية حقوق الإنسان للطفلة.

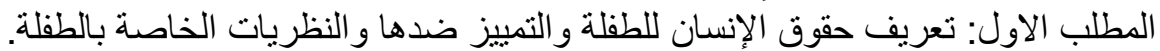

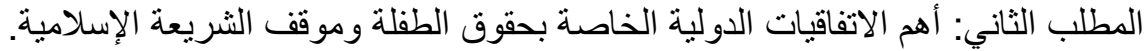
المبحث الثاني: حقوق الطفلة الأساسية. المطلب الاول: حقوق الطفلة الاقتصادية والاجنة الاجنماعية و الثقافية. المطلب الثاني: حقوق الطفلة المدنية والسية الطياسية الخاتمة.

\section{المبحث الأول ماهية حقوق الطفلة}

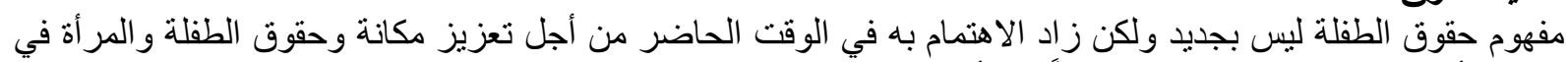
داخل الأسرة و المجتمع سنبحث ذلبك ولك وفقاً لما ليأتي: 


\section{مفهوم حقوق الطقلة وتمييز ضدها}

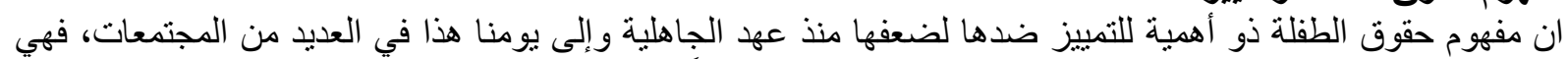

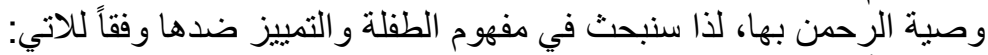

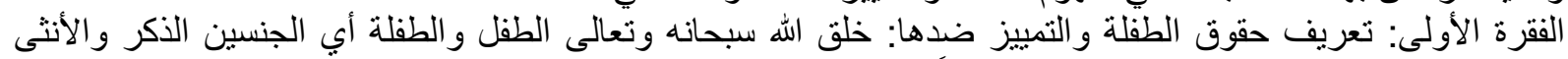

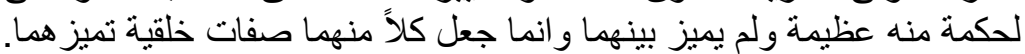

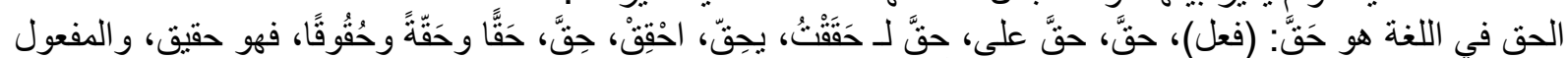

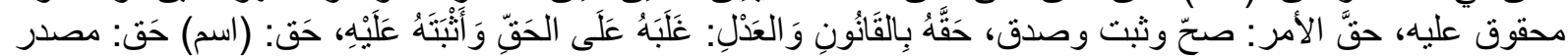

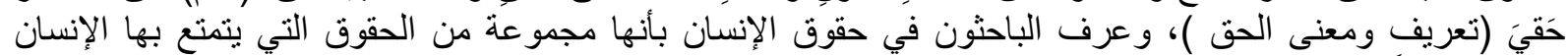

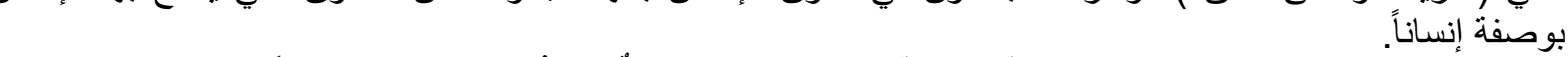

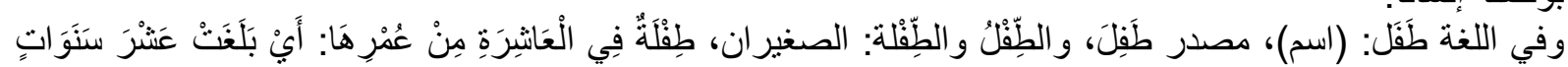
(أما تعريف الفتلة ) أو الطفلة في القانون الدولي: (وهن الأطفال الاناث التي تقل أعمارهن عن ثمانية عشر سنة) (Definition of terms)

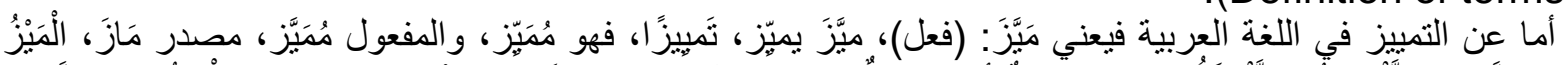

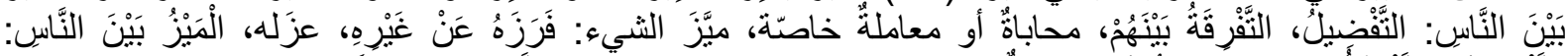

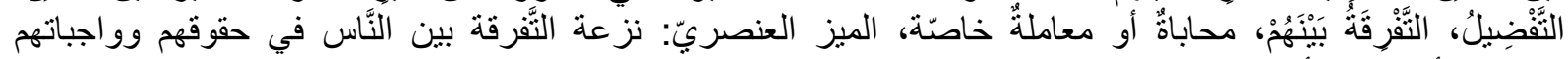

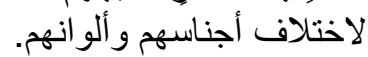

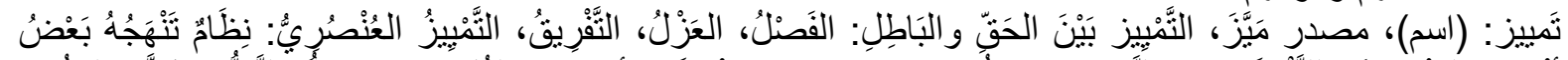

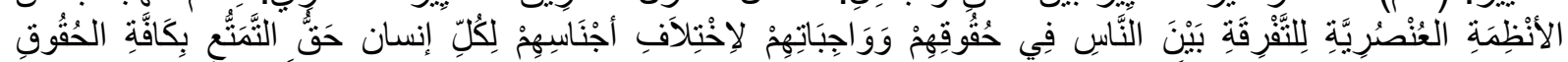

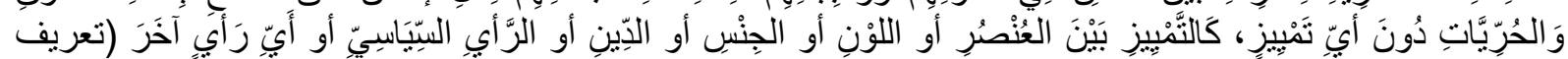

و ومعنى ميز ).

حقوق الطفلة هي حقوق الإنسان العالمية، وهي الحقوق الاقتصادية والاجتماعية و الثقافية و المدنية والسياسية، حقوق

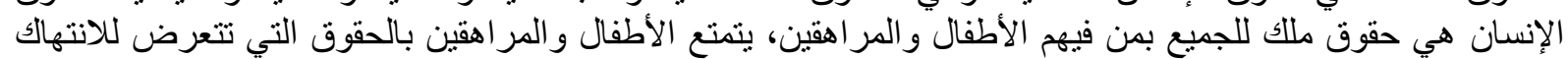

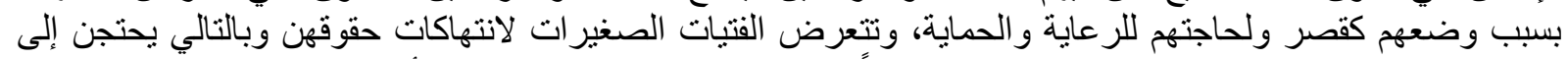

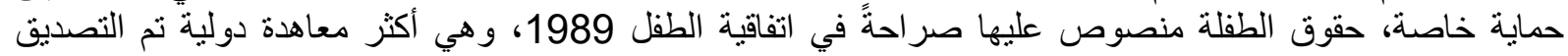

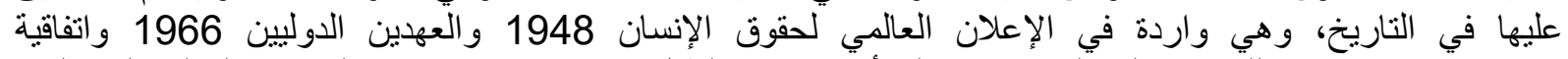
1979 للقضاء على آلتمييز ضد الإعلان المرأة، واتفاقية الطفل 1989 192DAW)

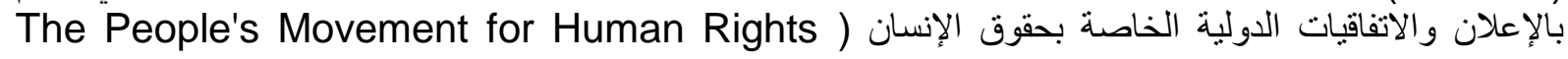
. (Education (PDHRE) / NY

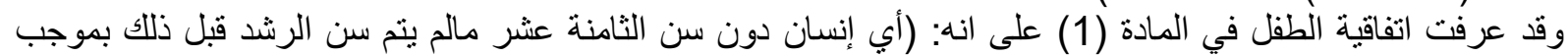

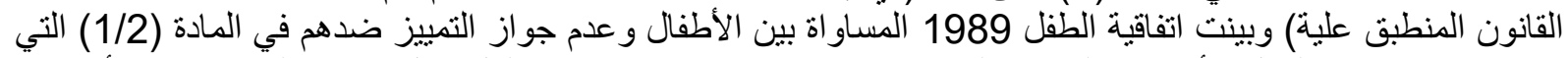

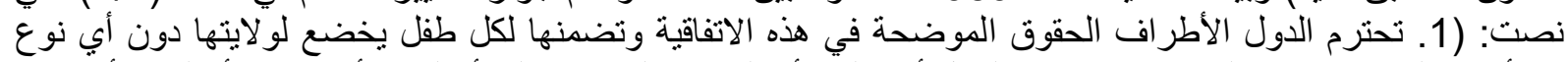

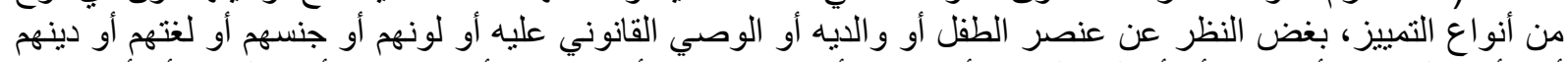

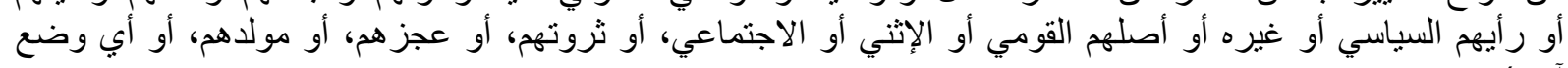

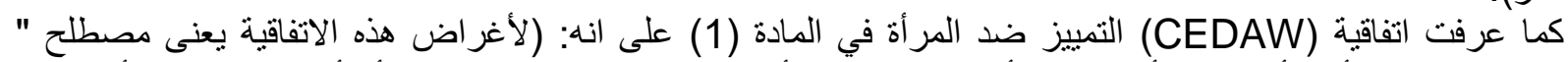

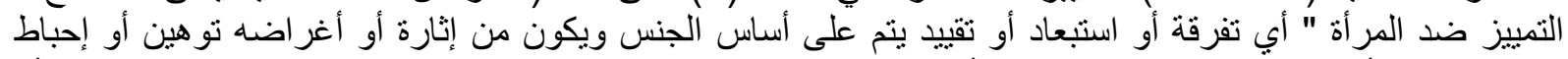

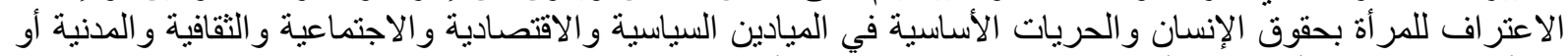

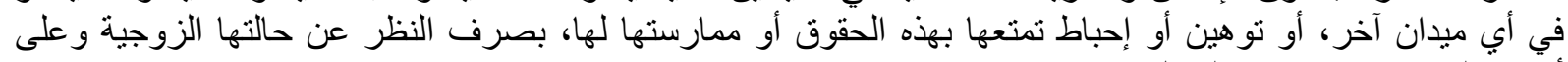
أساس المساو اة بينها وبين الرجل الرجل).

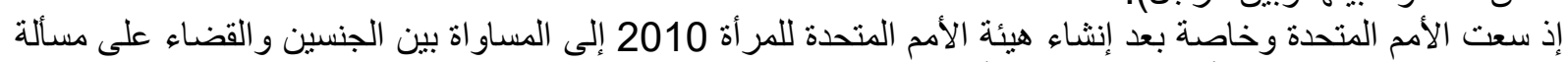

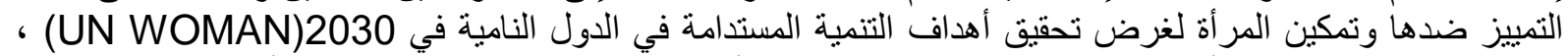

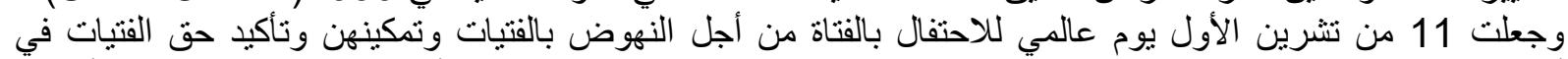

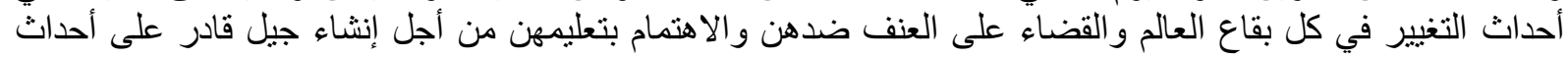

تغير اجتماعي (United Nations, 2020).

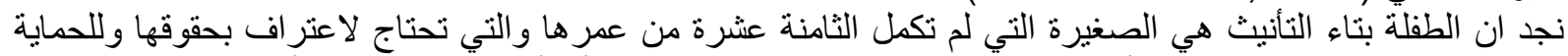

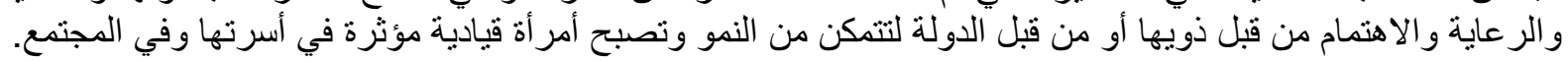




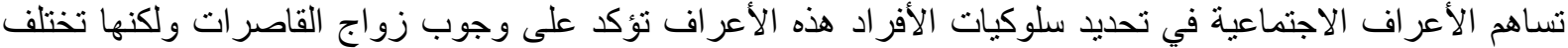

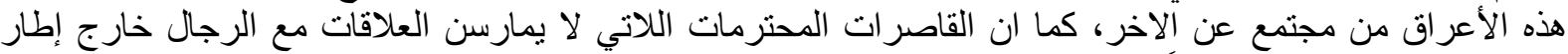

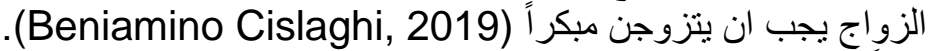
ثانياً: نظرية التغيير: وهي "الفتيات ليست عرائس" هذه النظرية تقوم على انهاء مسألة زواج القاصرات تقوم على

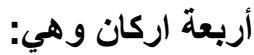

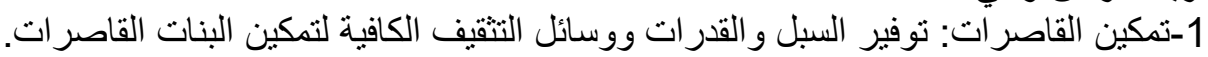

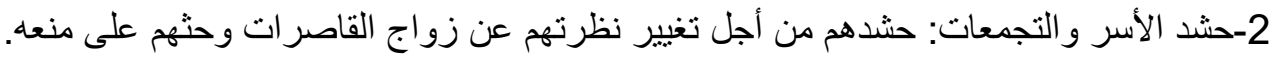

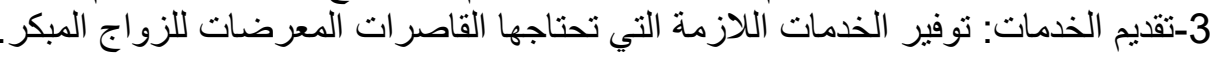

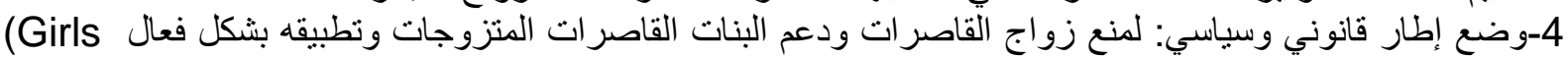
.Not Brides, 2014)

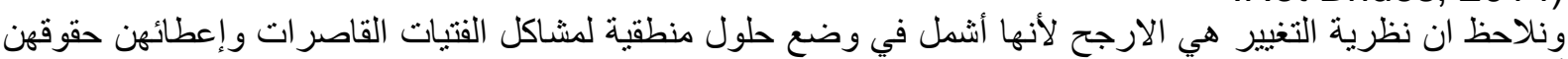

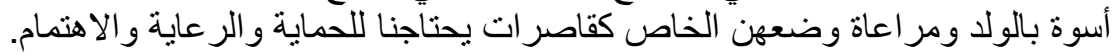

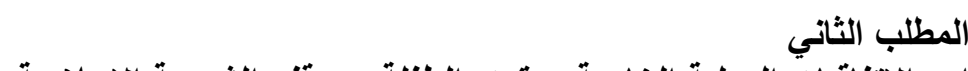 الهم الاتفاقيات الدولية الخاصة بحقوق الطفلة وموقف الثريعة الإسلامية}

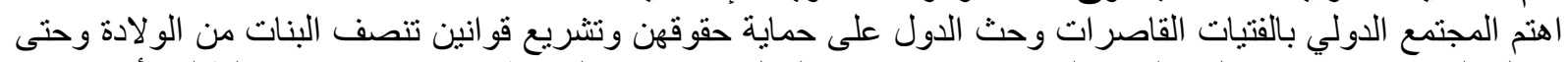

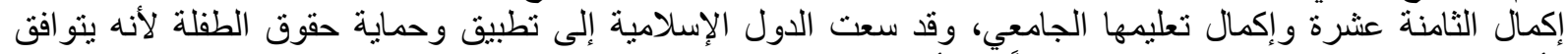

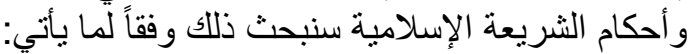

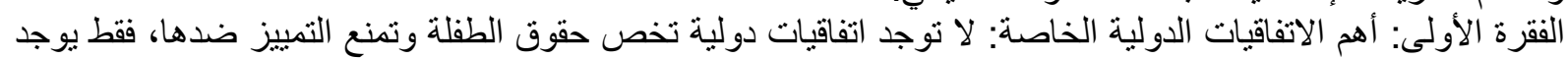

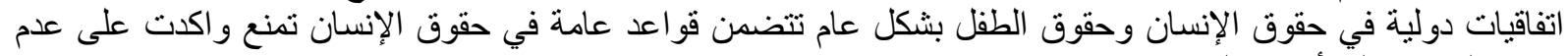
جواز التمييز على أساس الجنس الهمها:

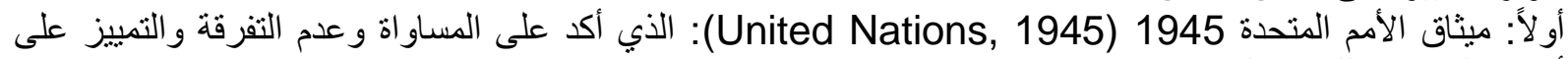

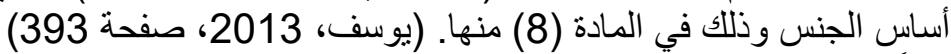

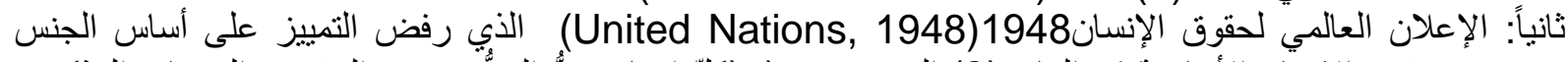

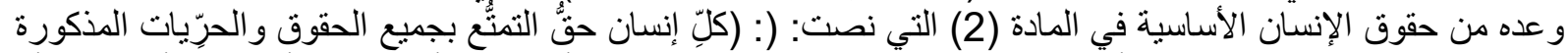

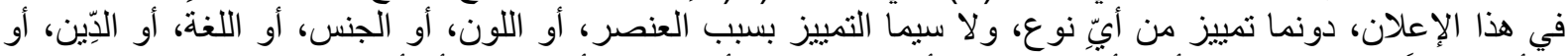

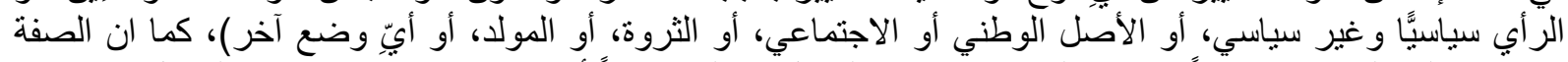

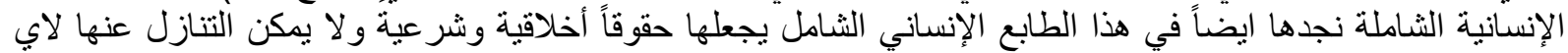

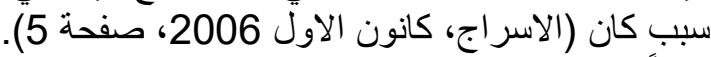

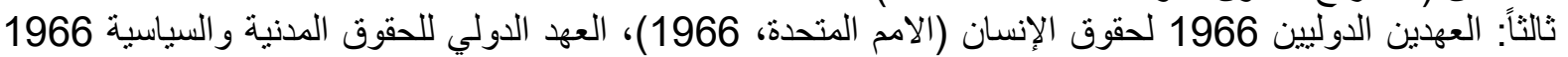

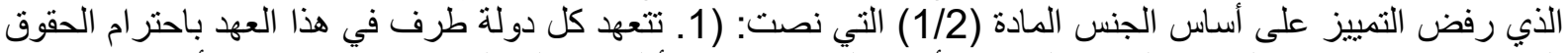

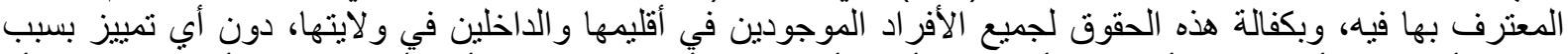

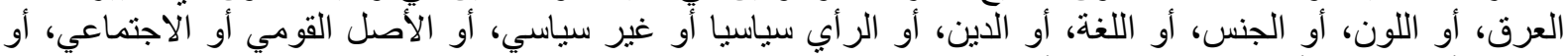

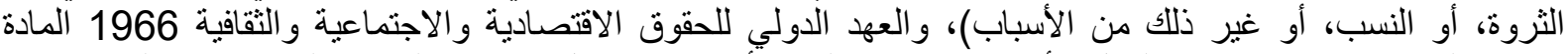

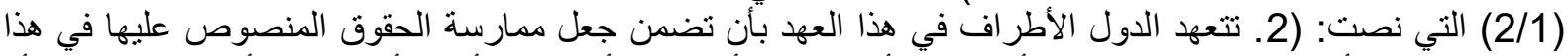

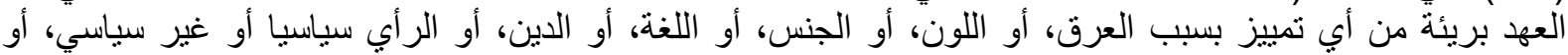

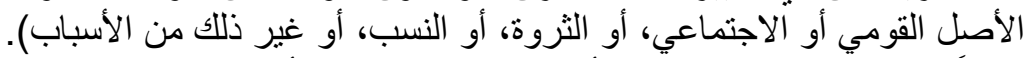

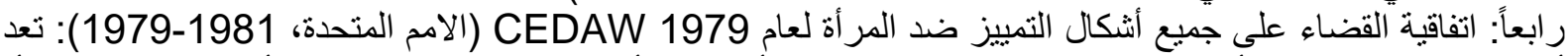

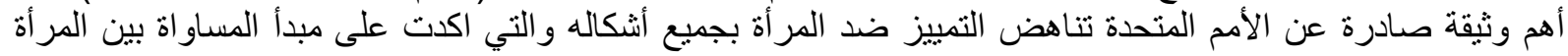

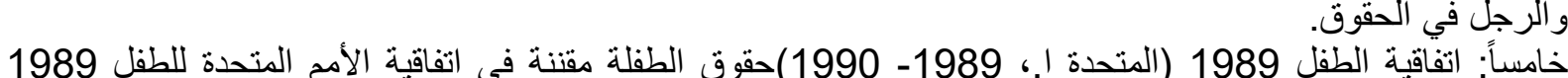

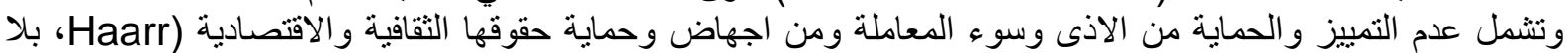

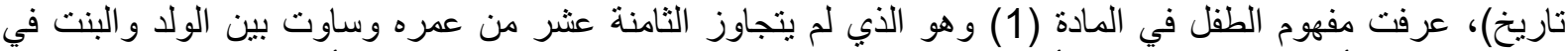

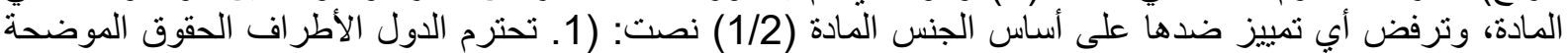

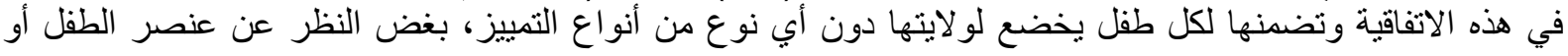


والديه أو الوصي القانوني عليه أو لونهم أو جنسهم أو لغتهم أو دينهم أو رأيهم السياسي أو غيره أو أصلهم القومي أو

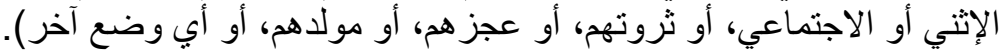

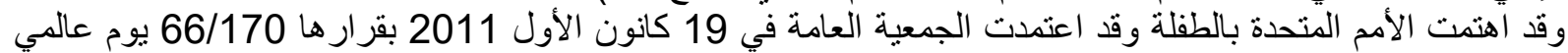

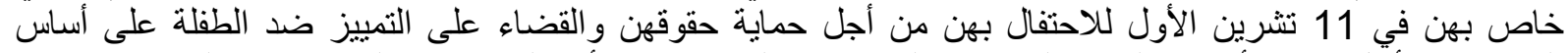

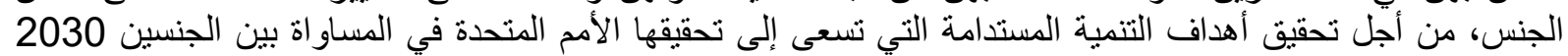

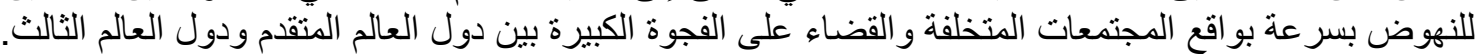

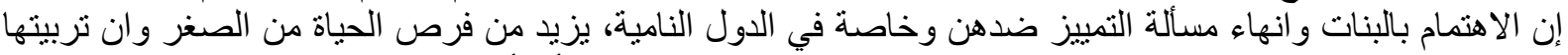

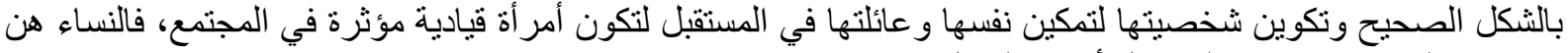

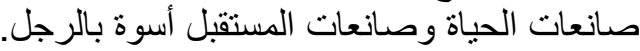

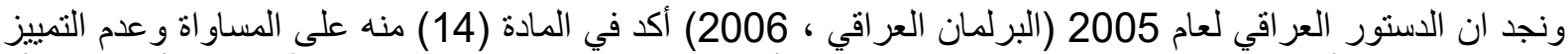

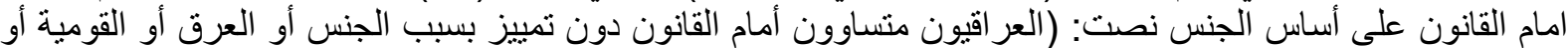

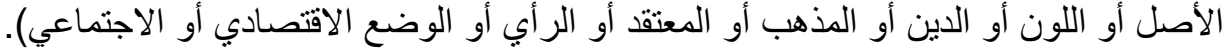

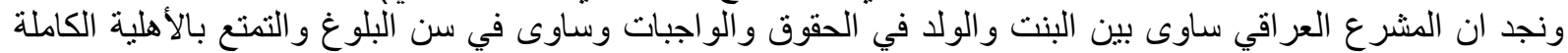
و وهي إكمال الثامنة عشر سنة الثرانة

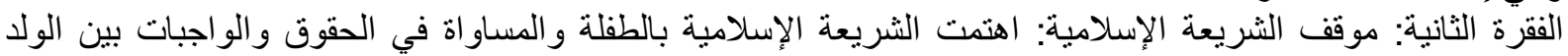

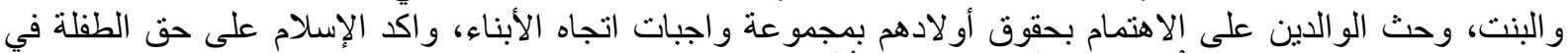

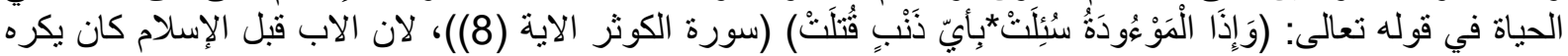

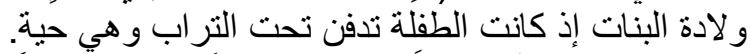

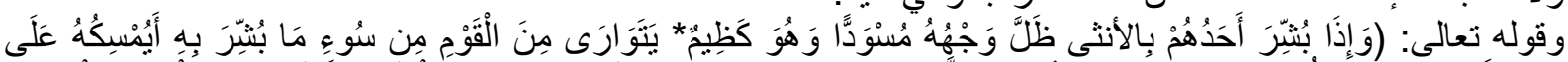

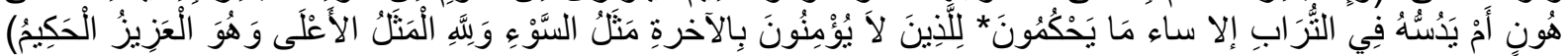

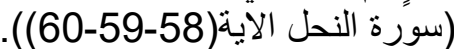
الكظيم وهو المملوء بالغيض من دواليض دون ان بتكلم وجهة مسوداً أي كئيباً وينوارى أي يخفي نفسه من الناس وكأن الخزي و العار لحق به، ام يقوم بو أد الطفلة ليخفي العار الذي لحق به وذللك لعدم ايمانهم بالله سبحانه وتعالى (ابن كثير ، 1420هـ

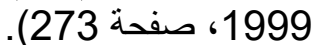

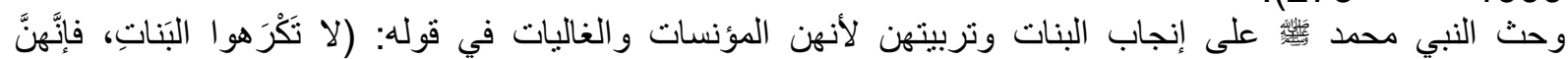

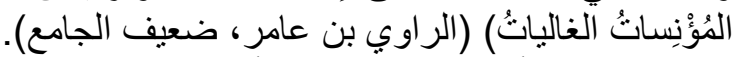

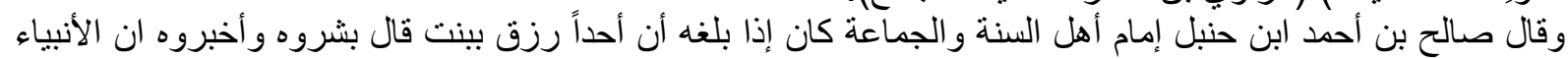

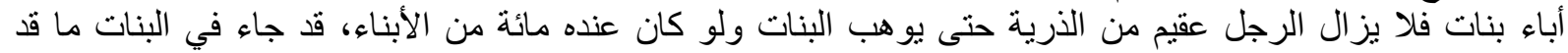
علمت بـاء. وقال يعقوب بن بختان: ولد لي سبع بنات، فكنت كلما ولد لي ابنة دخلت على احمد بن حنبل فيقول لي: يا ابا يوسف

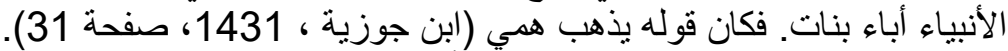

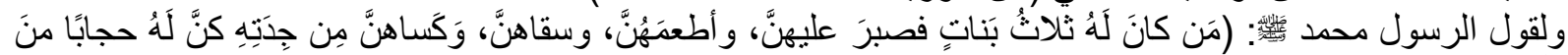

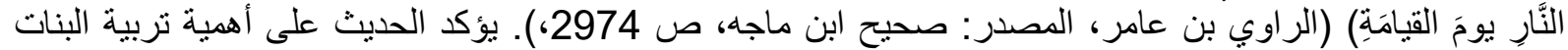

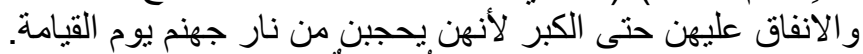

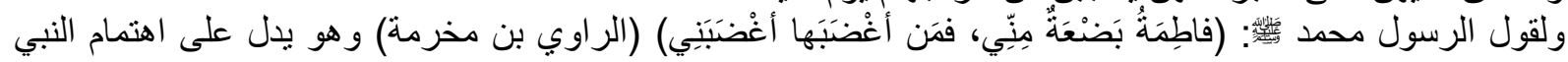

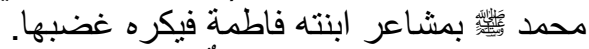

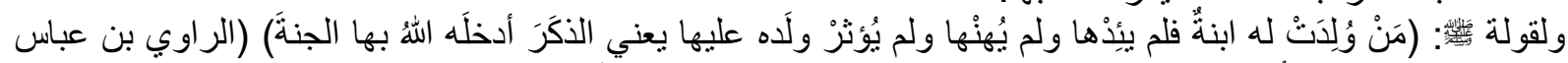

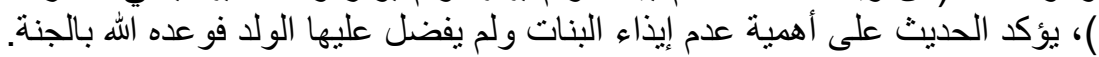

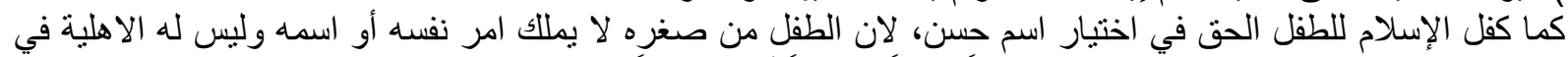

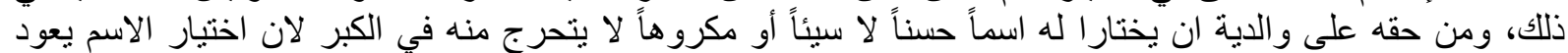

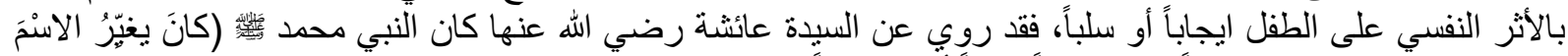

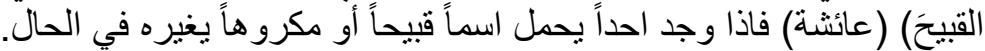

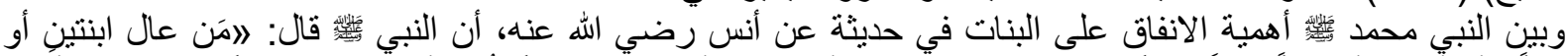

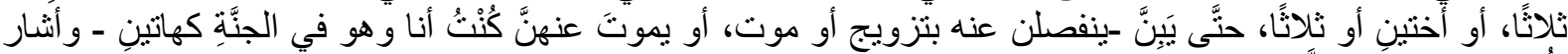

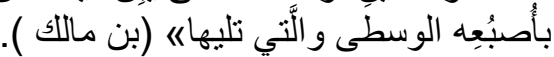

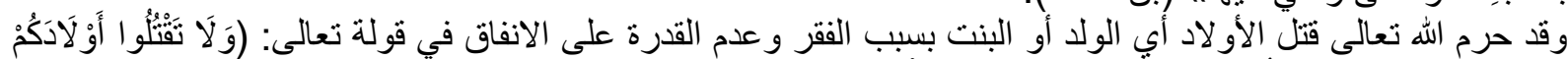

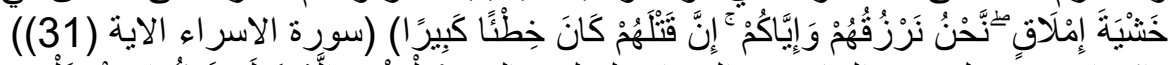

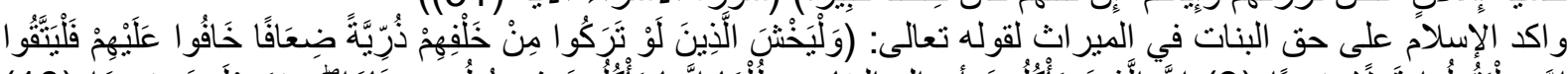

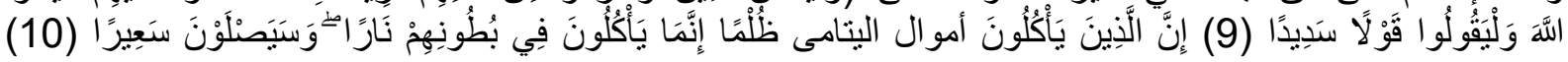




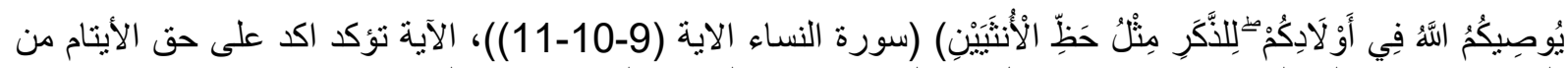

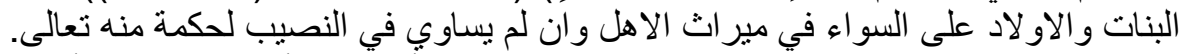

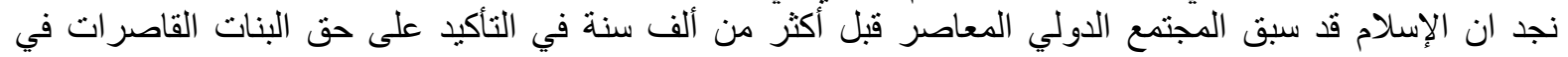

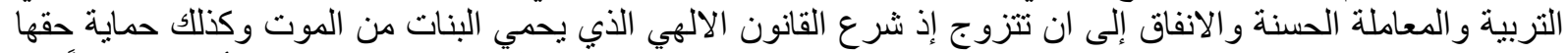

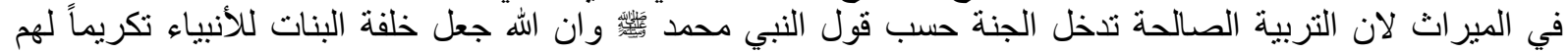

\section{الحقبث الأثنأسية للطفلة}

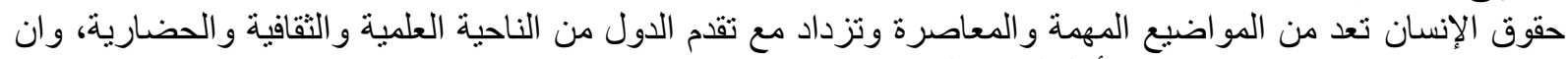

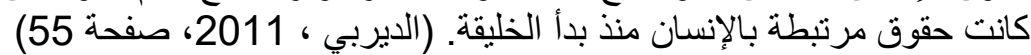

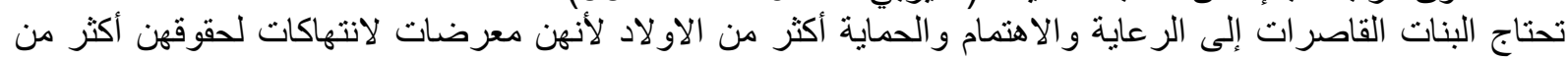

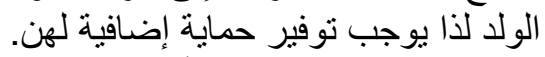
تعد اتفاقية الطفل 1989 أكثر اتفاقية مصادق علية عليها في التاريخ وهي اتفاقية حقوق الإنسان للأطفال على السواء بين

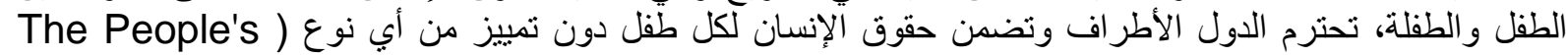
الطفل Movement for Human Rights Education (PDHRE) / NY

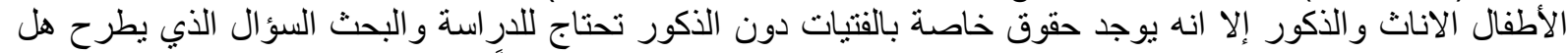

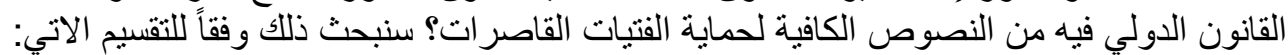
المطلب الأول الأول الحقوق الخاصة الحنة إن من أهم الحقوق هي الحقوق الثخصية أي المرتبطة بشخص الإنسان و لا يمكنه الاستخناء عنها إلا أن مفهومها يختلف

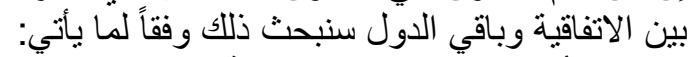

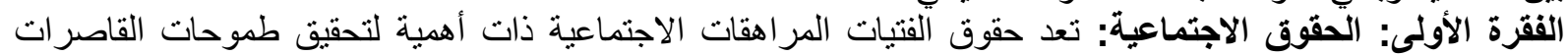

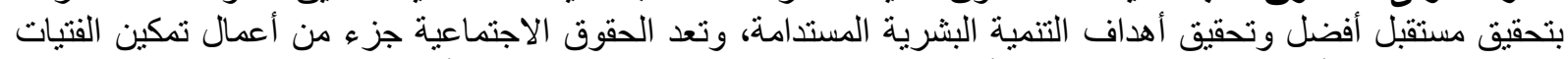

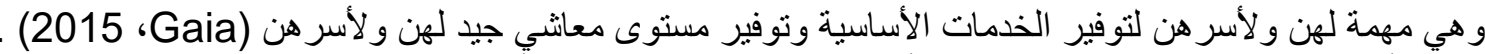

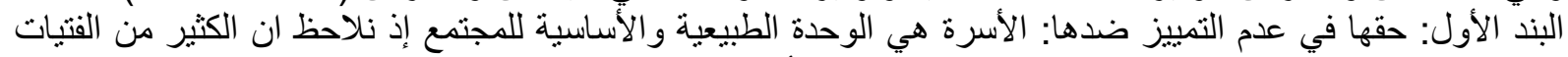

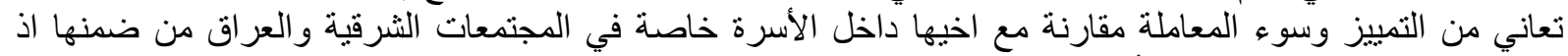

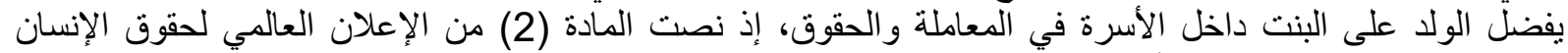

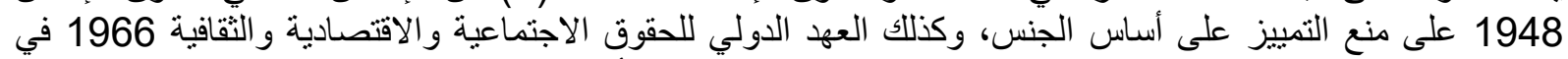

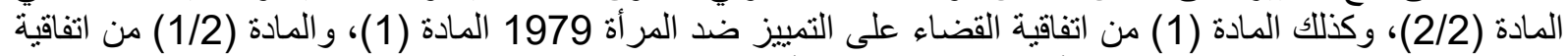

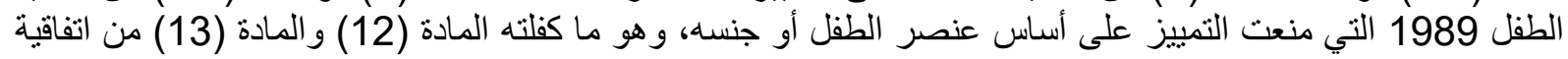

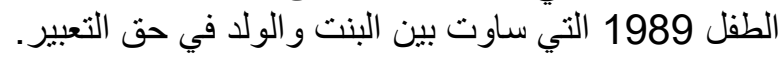

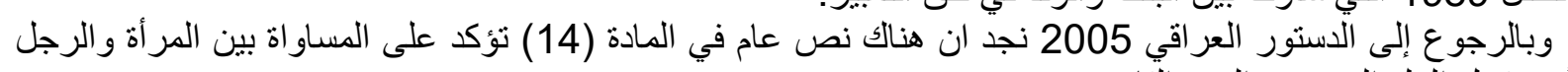

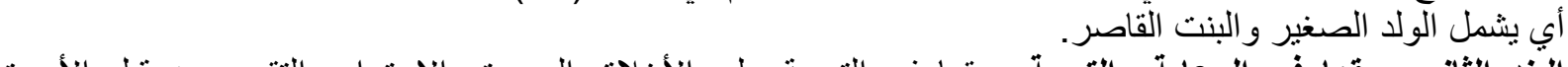
البند الثاني: حقها في الرعاية والتربية: حقية الثها في التربية على الأخلاق الحميدة والاحترام والتقدير من قبل الأسرة

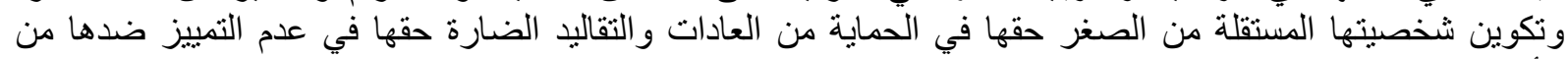

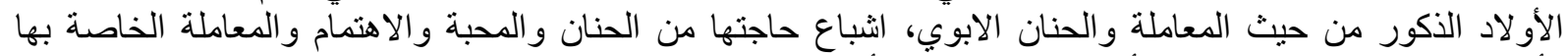

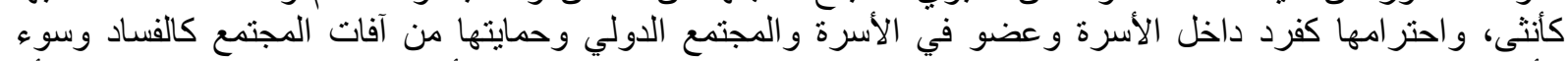

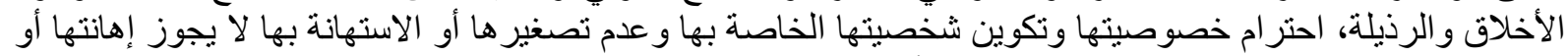

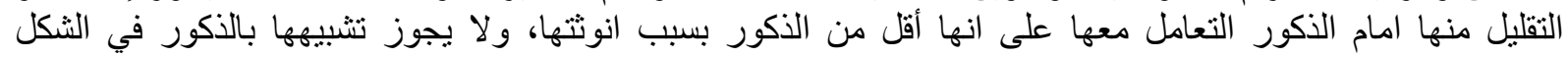

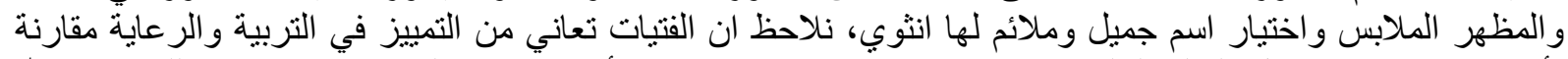

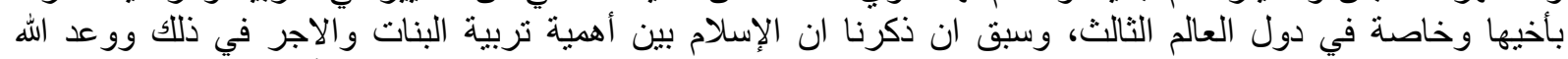

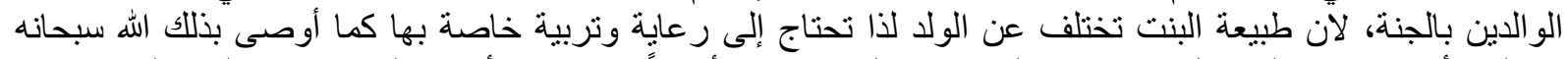

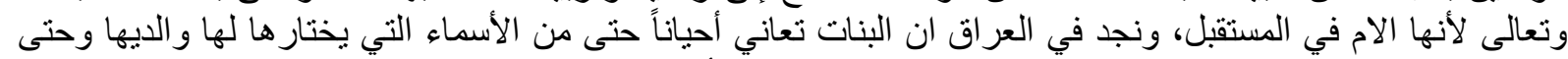

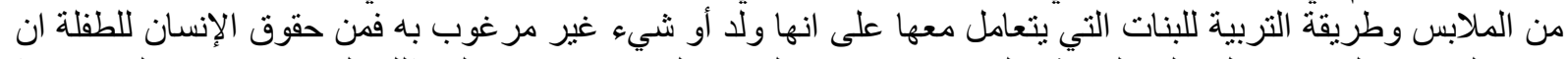

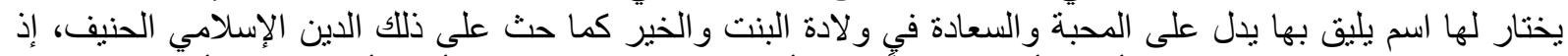

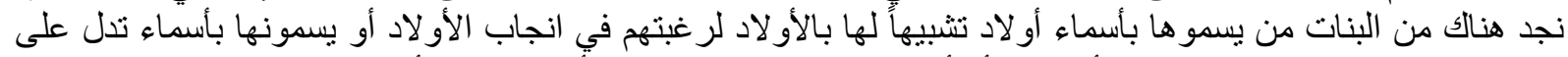

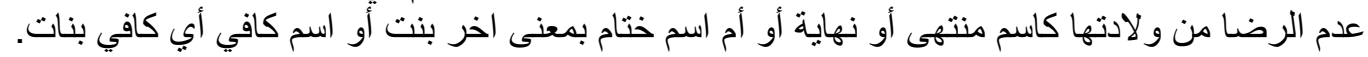




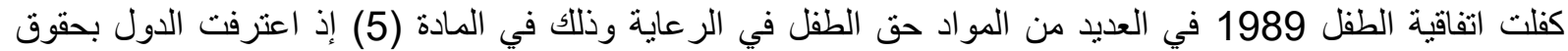

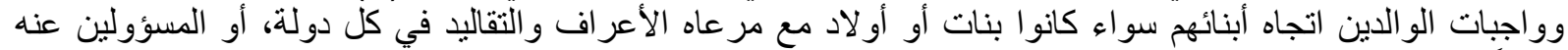

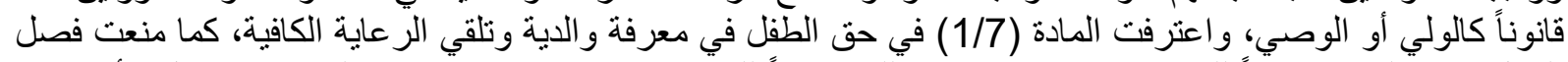

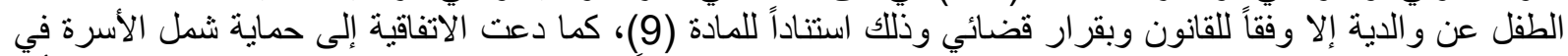

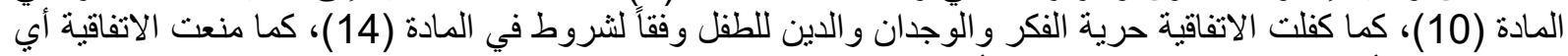

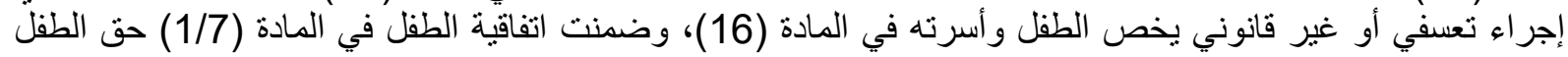

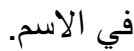

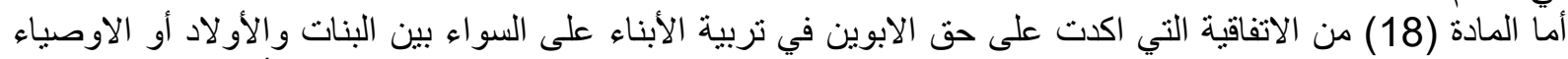

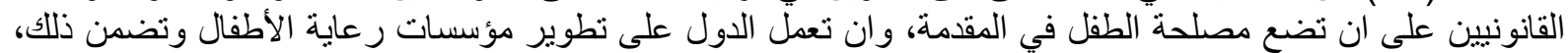

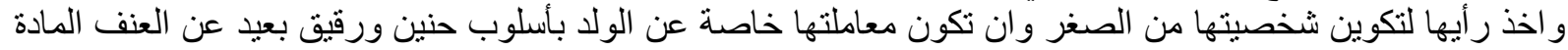

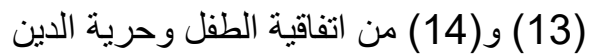

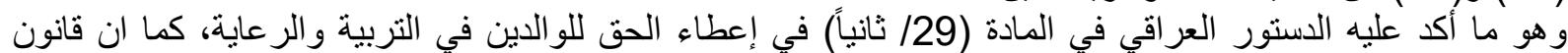

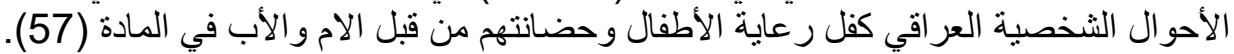

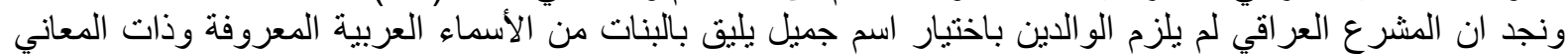

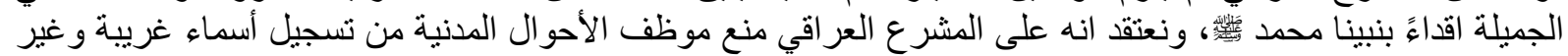

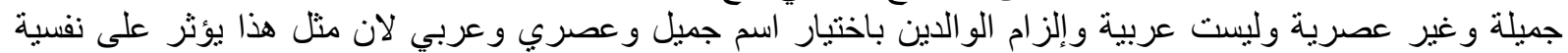
الطفل وحتى الكبر.

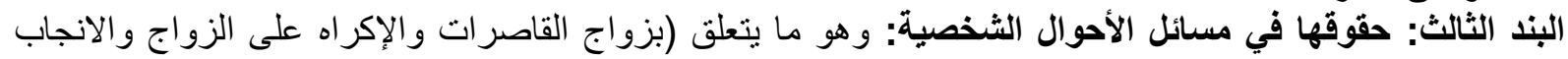

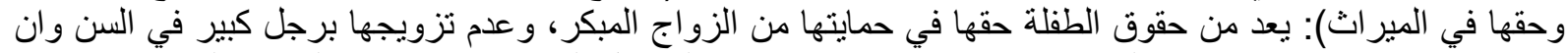

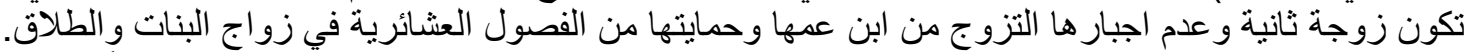

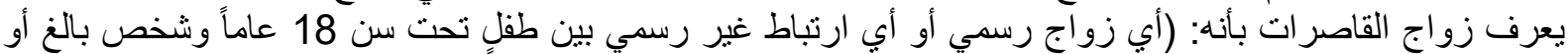

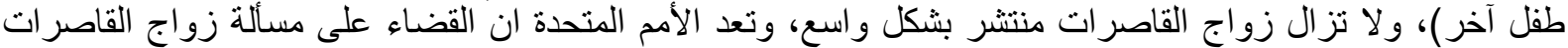
من أهدافها لتحقيق أهداف التنمية المستدامة في

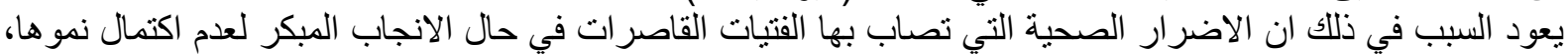

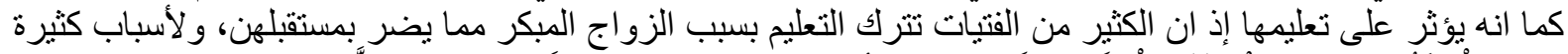

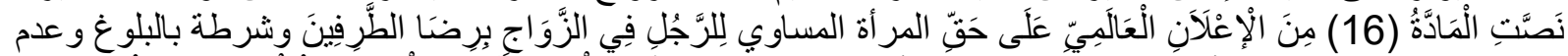

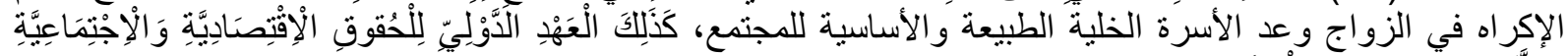

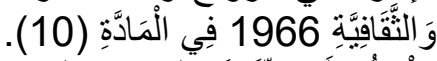

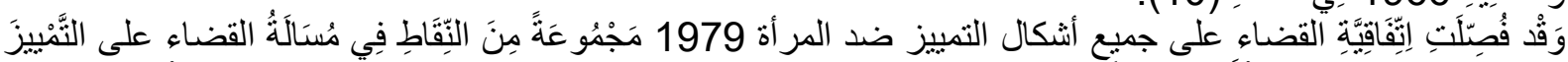

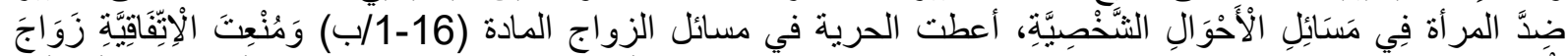

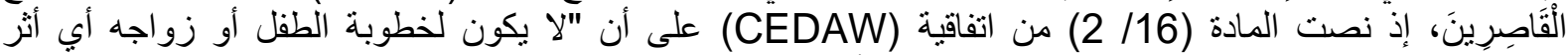

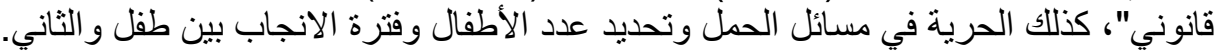

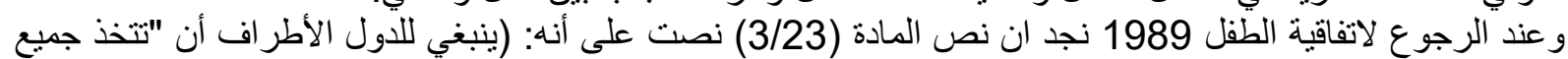

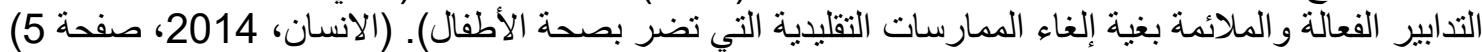

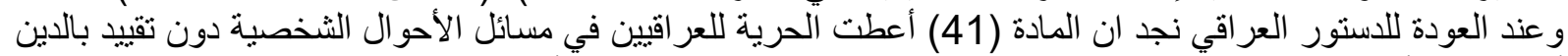

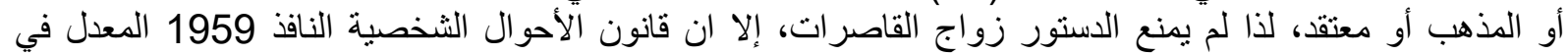

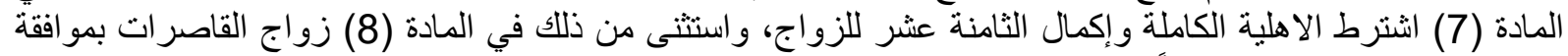

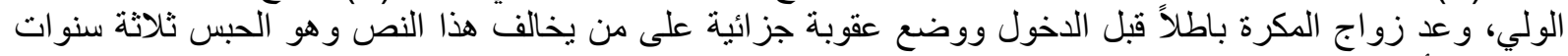

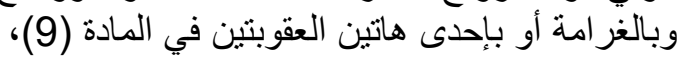

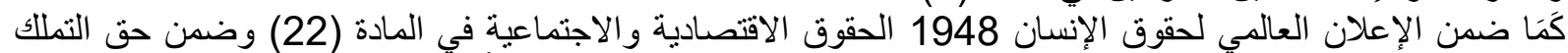

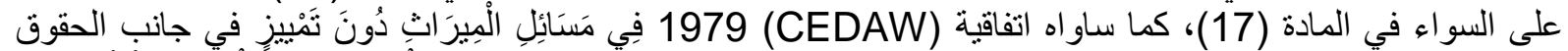

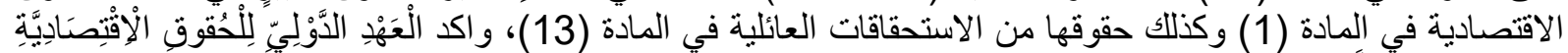

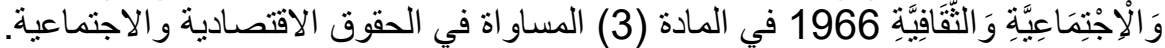

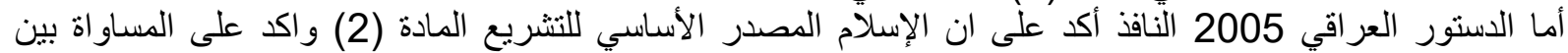

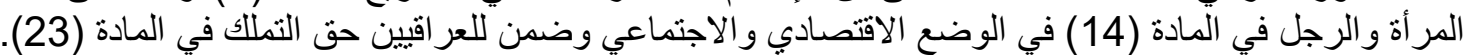

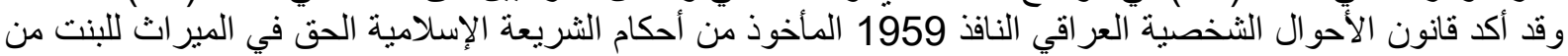
و الديها أو جديها للذكر مثل حظ الانثيين في المادة (189 1 ) سواء كانت قاصر أو أو بالغة متزوجة الو أو غير متزوجة. 


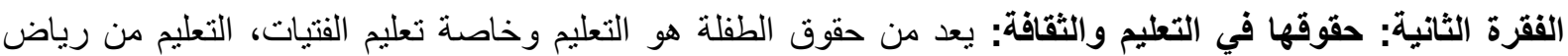

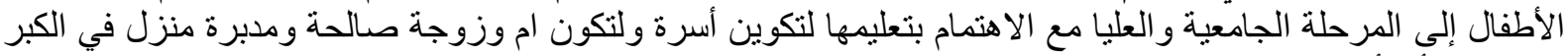

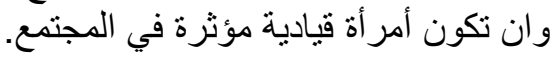

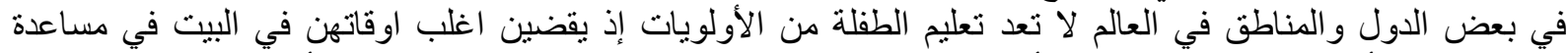

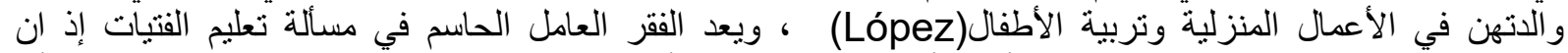

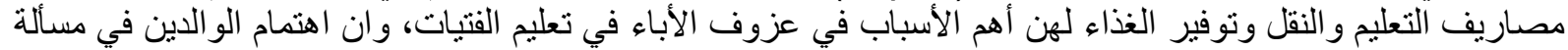

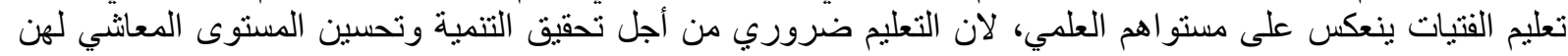

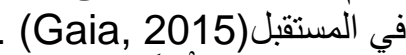

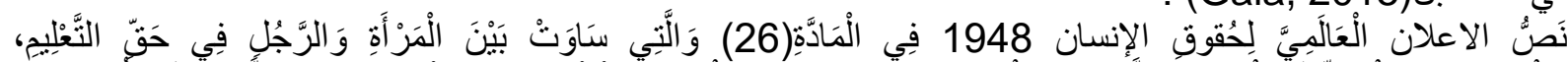

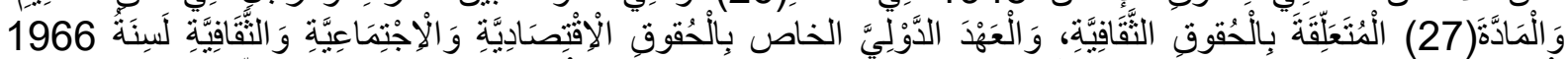

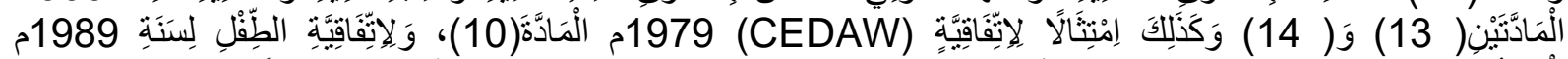

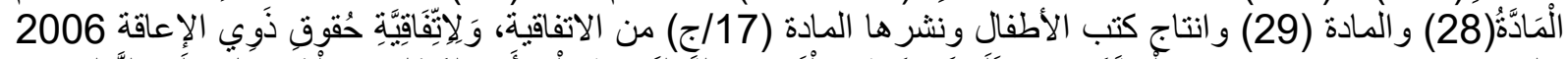

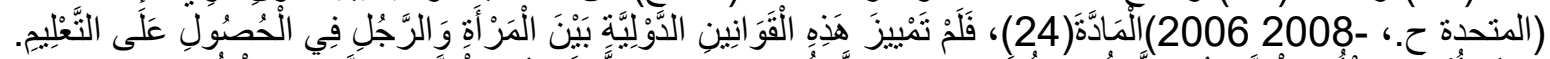

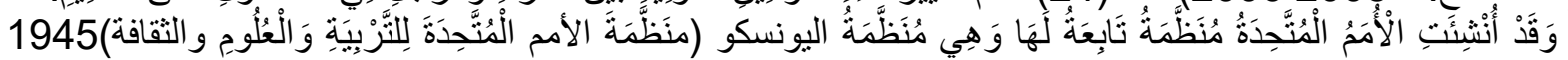
UNESCO (United Nations Educational, Scientific and Cultural Organization) اتفاقية مكافحة التمييز ضد التعليم 1960 (والتعليم، -1962 1960) والتي اكدت في المادة (1) على عدم جواز التمييز

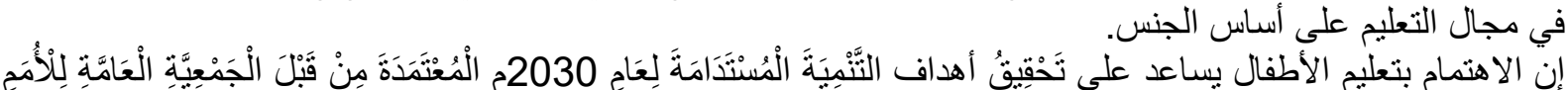

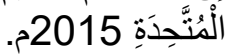

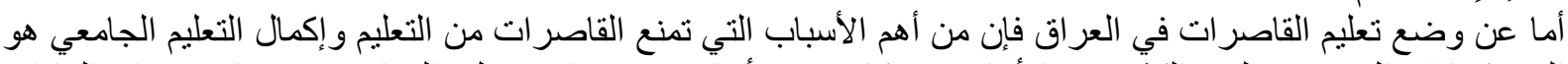

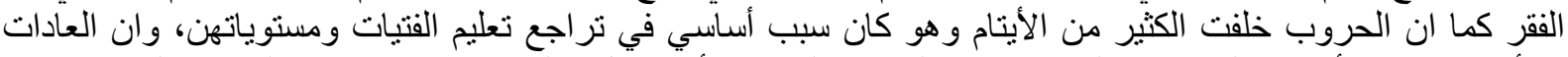

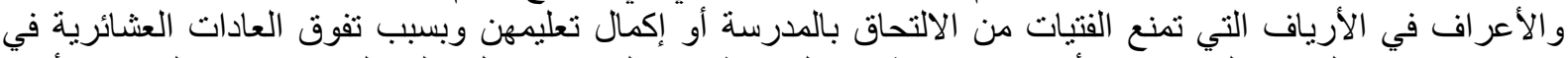

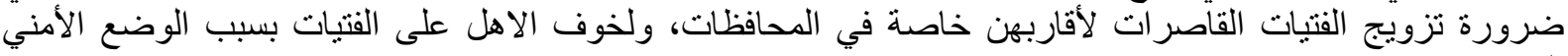

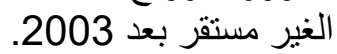

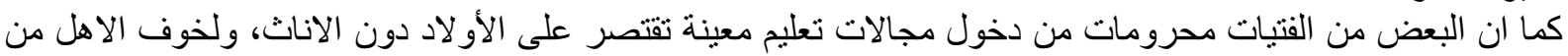

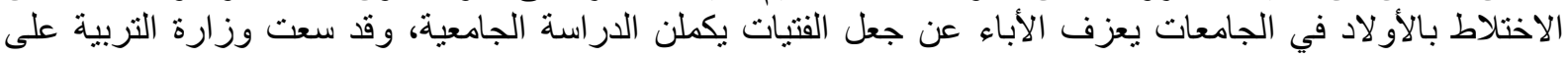

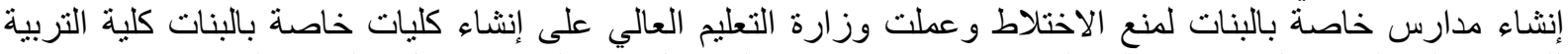
للبنات وكلية التربية الرياضية وكلية الثريعة الإسلامية- قسم البنات لتمكين البنات لإكمال تعليمهن الجامعي في مجالات التيات

ير غبونها.

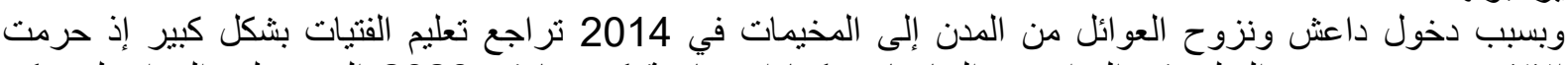

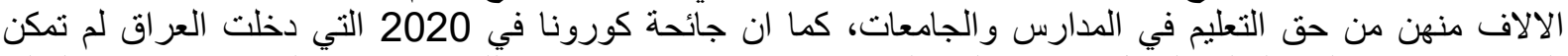

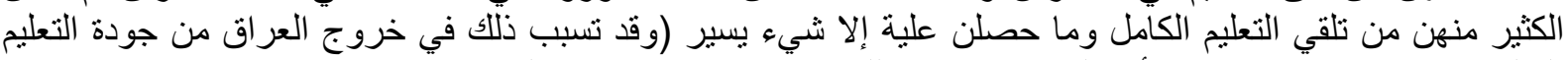

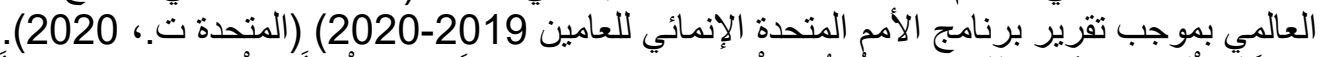

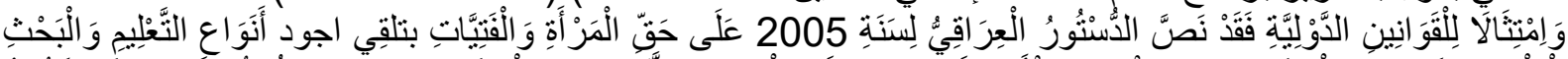

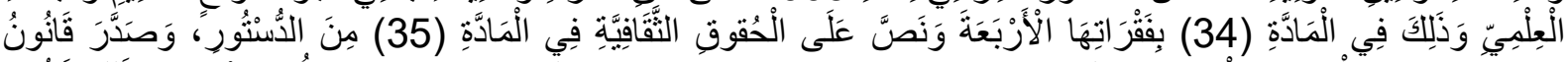

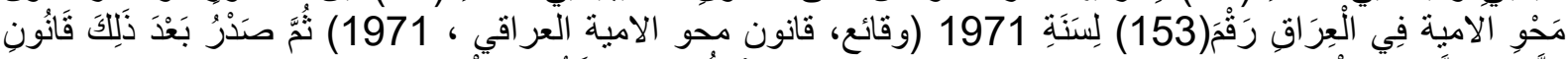

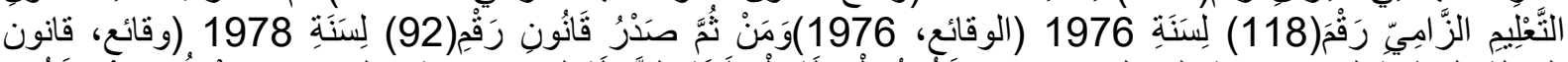

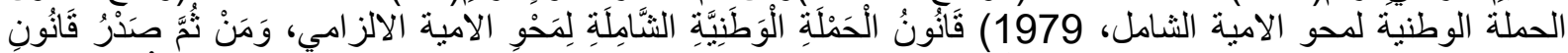

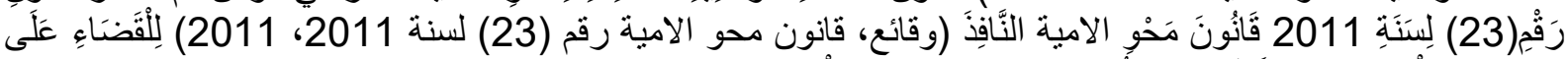

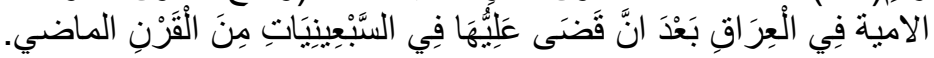

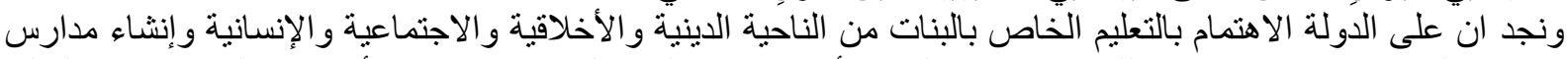

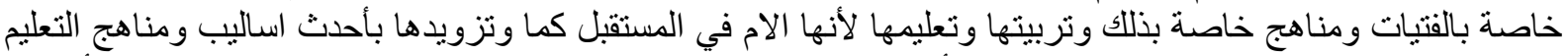

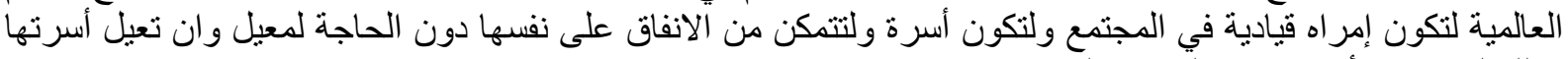

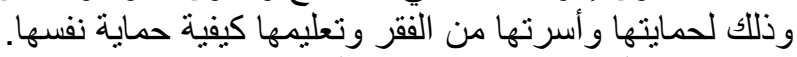

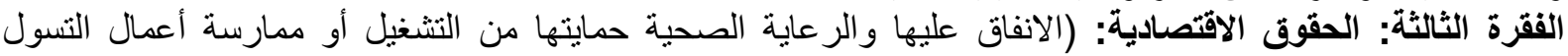

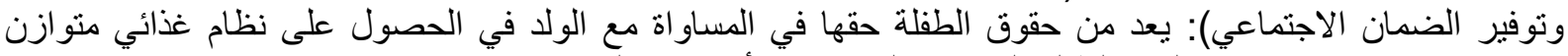
وتوفير مستوى معانشي ملائم لنمو الطفلة الفكري و الجسدي والأخلاقي و النفسي ( The People's Movement for وثرفئ) (Human Rights Education (PDHRE) / NY 
تشغيلها في الدور كخادمة أو ان تعمل في الثوارع لبيع حاجات (اتفاقية منظمة العمل الدولية بشأن الحد الأدنى للسن رقم

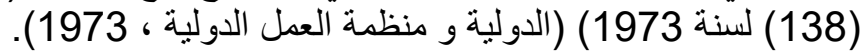

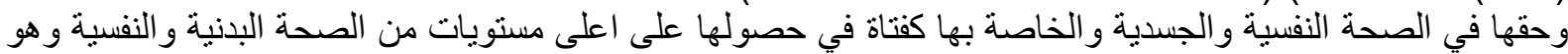

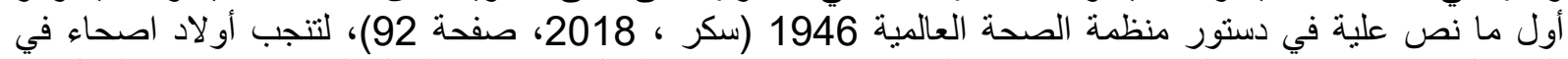

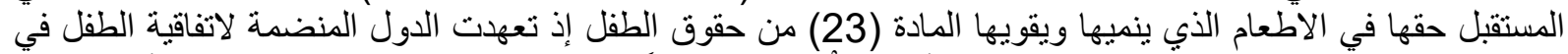

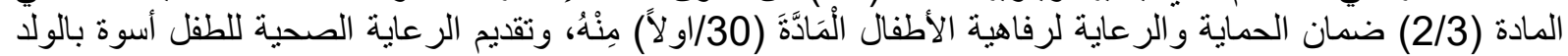

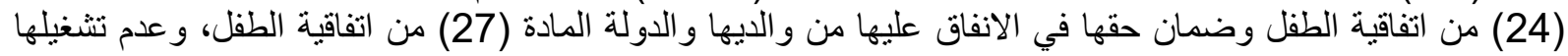

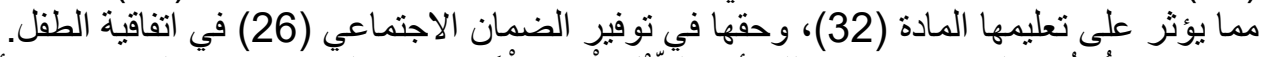

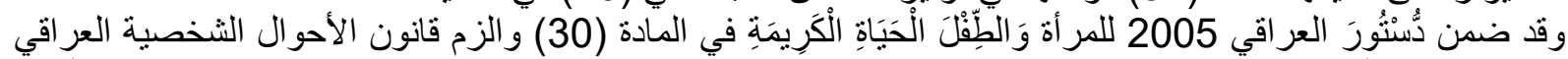

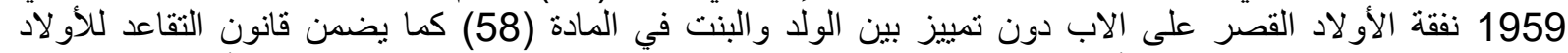

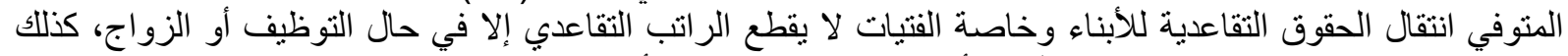

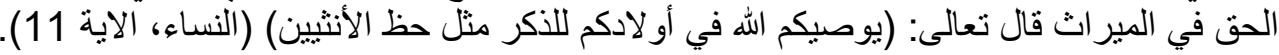

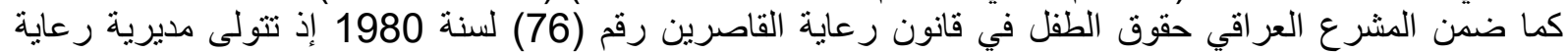

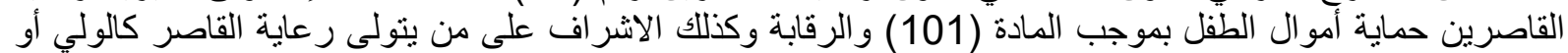

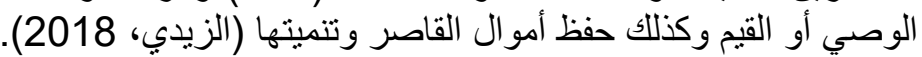

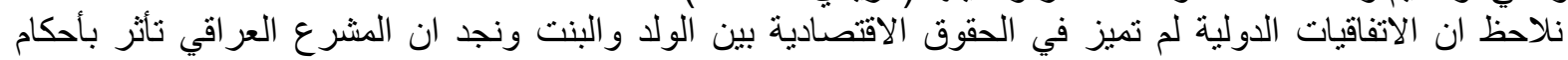

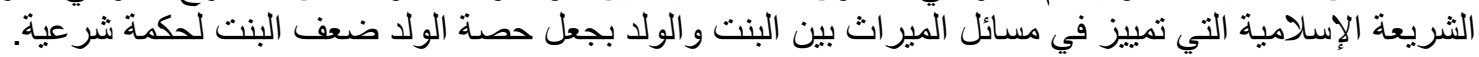

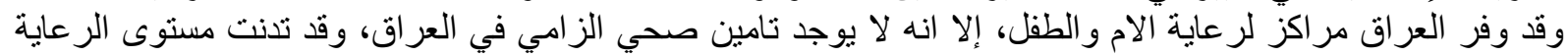

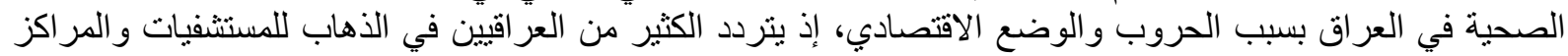

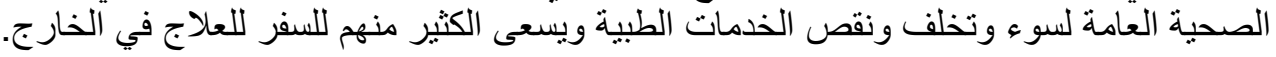

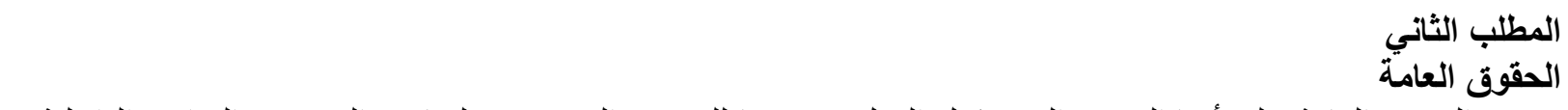
تعرف الحقوق العامة على أنها الحقوق التي تتكفل الدول بتوفيرها للثعب و التي نص عليها في الدستور و القو انين الداخلية

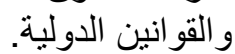

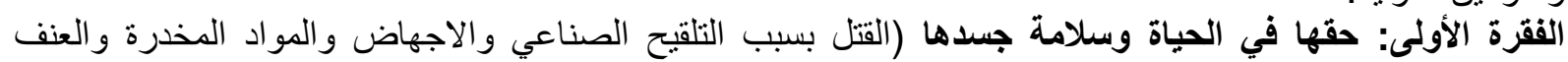

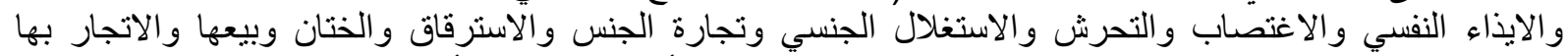

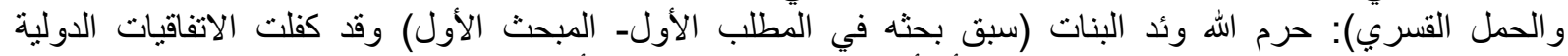

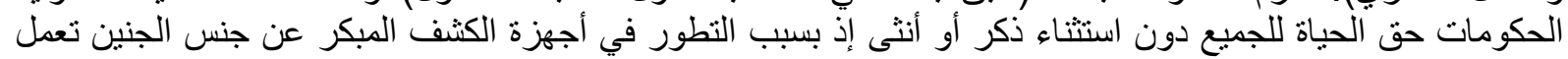

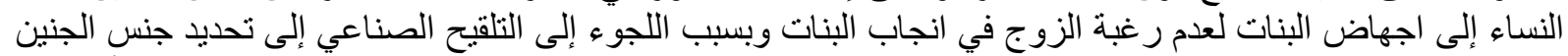

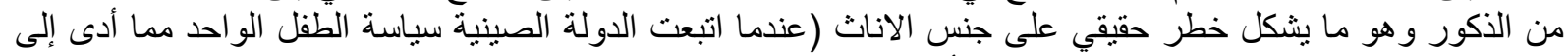

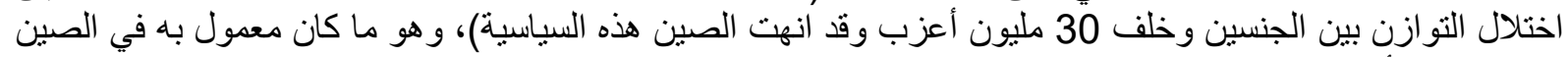

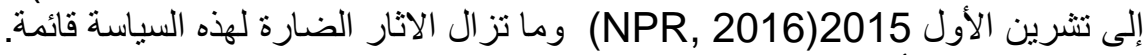

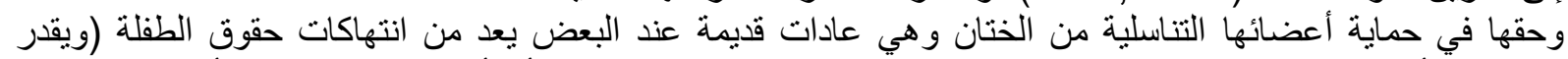

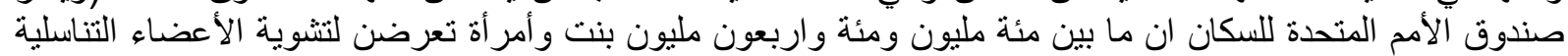

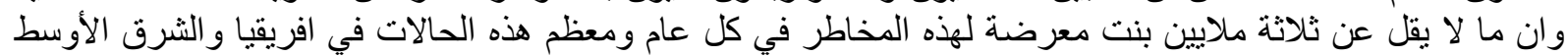

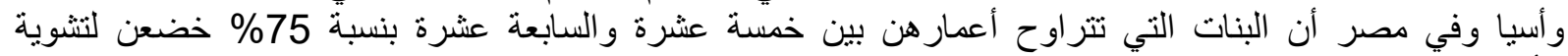

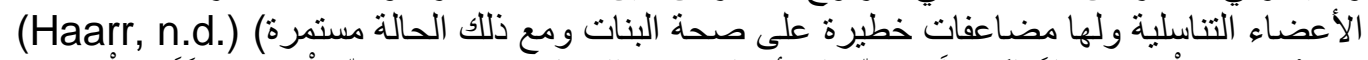

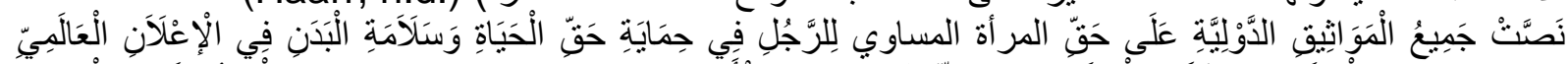

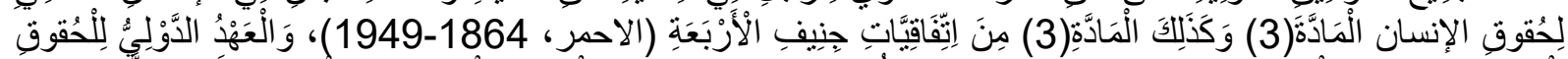

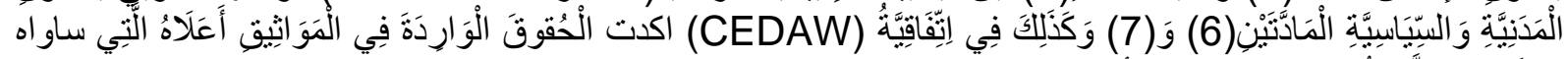

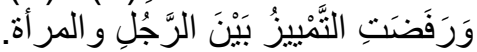

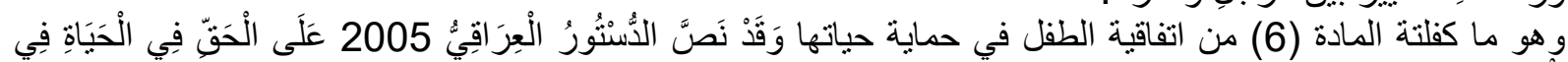

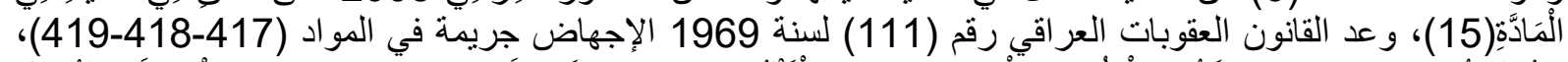

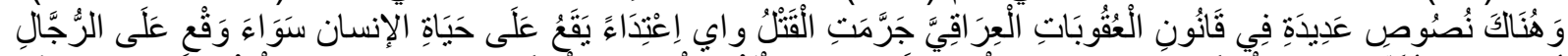

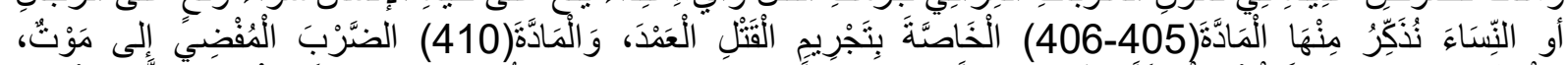

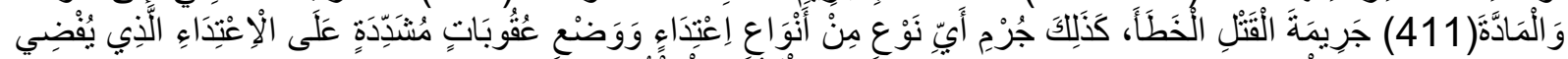

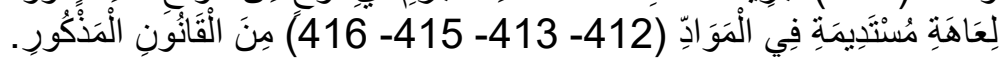




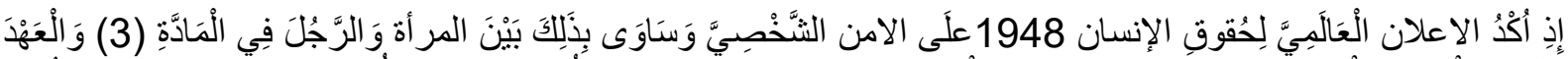

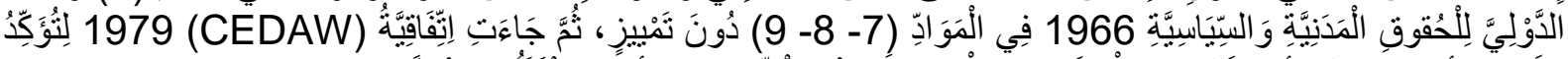

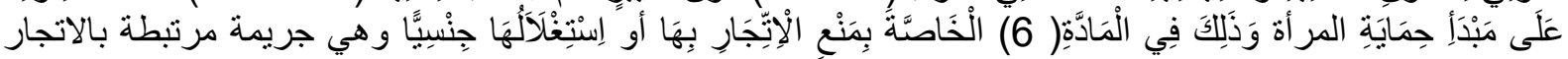

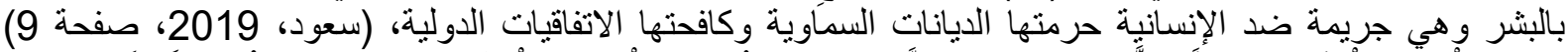

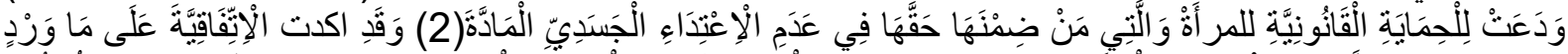

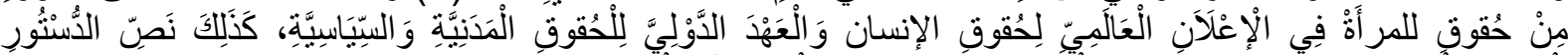

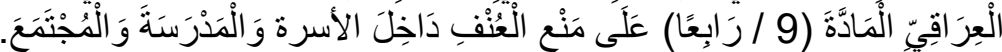

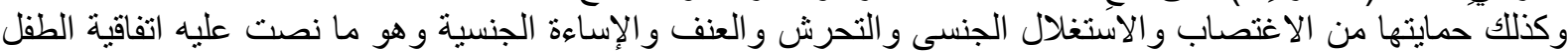

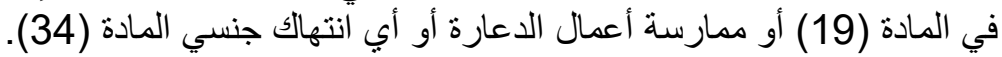

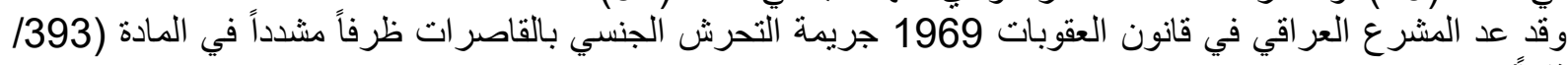
ثنانياً).

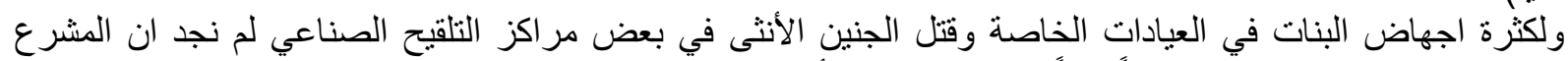

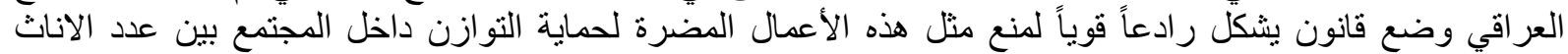
و والذكور. ولم يثدد القانون العراقي العقوبات على الاتجار بالفتيات وجر ائم الاغتصاب ولم يشدد العقوبات على تجارة الجنس التي التي

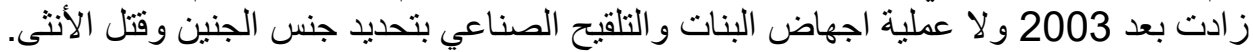

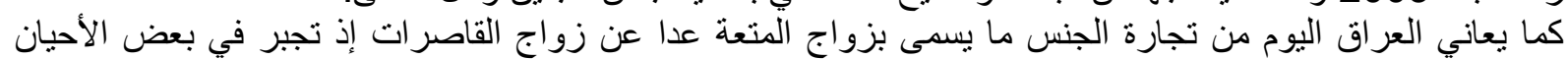

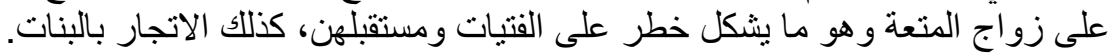

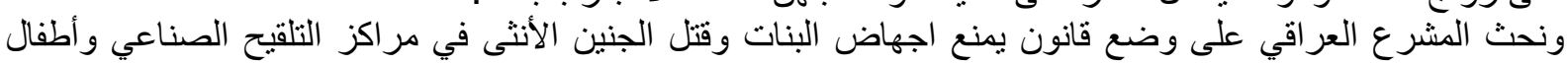
الانابيب.

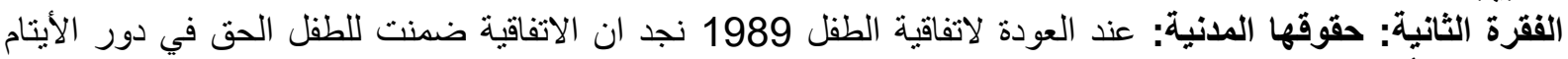

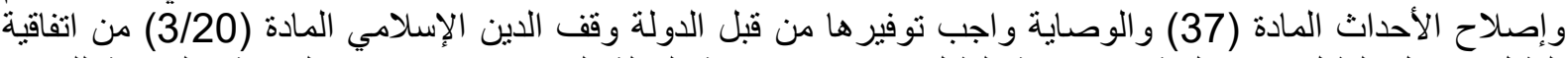

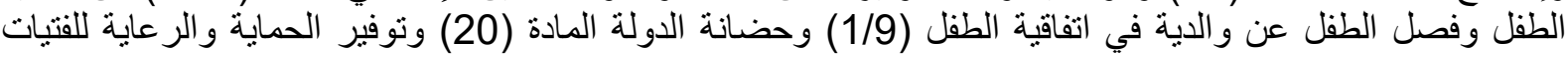
ذو ات الإعاقة وحقها في ان يكون لها ولي في حال وفاة والديها و المساو الة امام القانون و المثنول امام القضاء وحقها في في

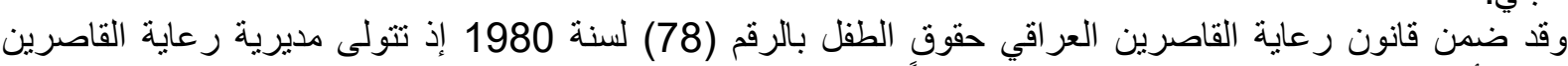

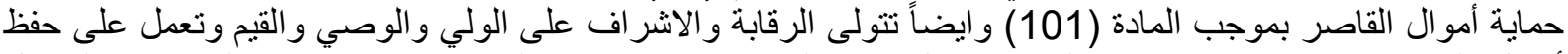

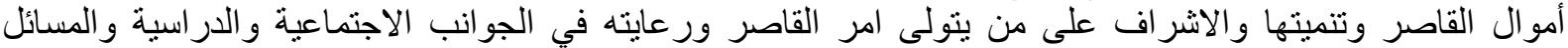

القانونية.

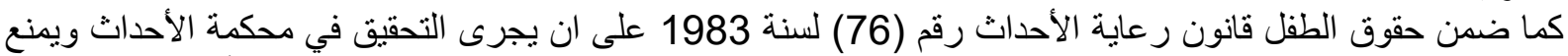

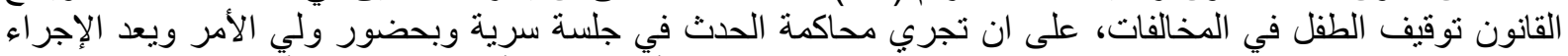

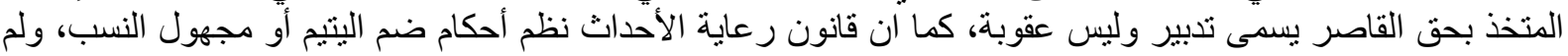

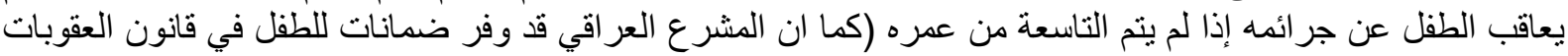

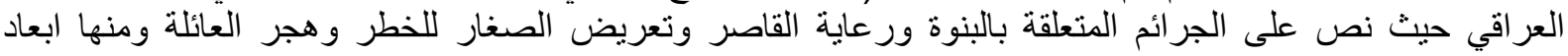

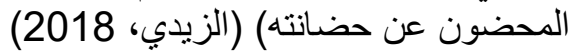
اتفاقية مناهضة التعذيب وغيره من ضروب، الزئن المعاملة أو العقوبة القاسية أو اللاإنسانية أو المهينة 1984. (المتحدة ا.،

الفقرة الثالثة: حقوقها السياسية: حقها في ان تحمل اسم وجنسية ابويها، وجنسية الدولة التي ولدت فيها أو التي تعيش

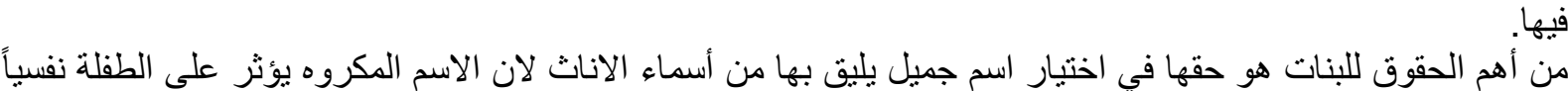

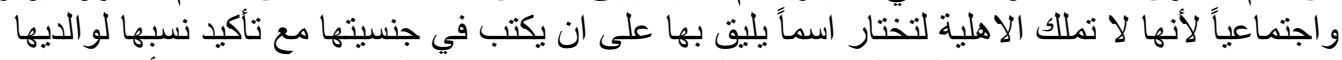

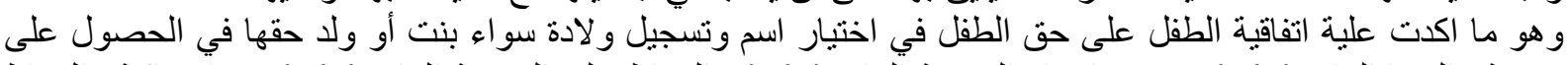
جنسية والديها المادة (1/7) وتجنب انعدام الجنسية المادة (2/7) و الحفاظ على الجنسية المادة (1/8) من الاتفاقية و الحفاظ على الهوية.

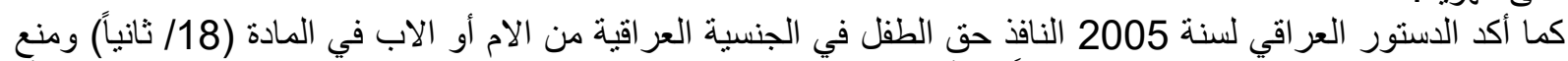

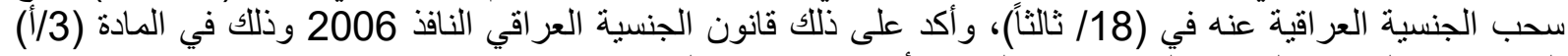
التي نصت على منح الجنسية العر اقية من ولد لاب أو لأل الام عر اقية. (الزيادي، 2018، صفحة الجنة 


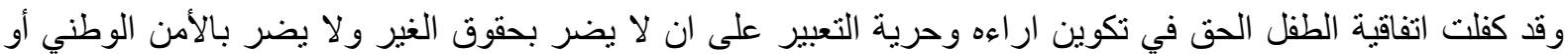

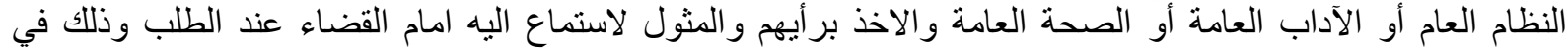

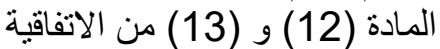

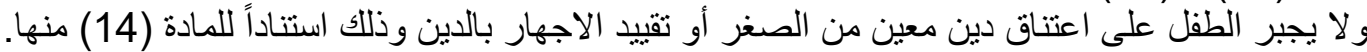

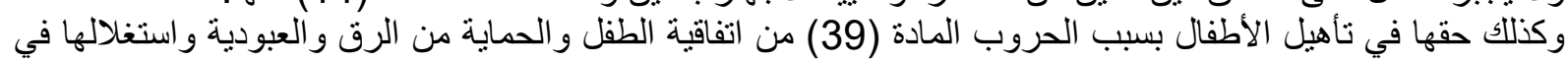

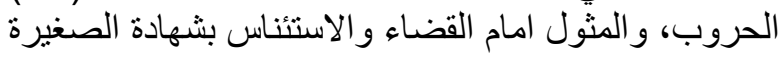

الخاتمة

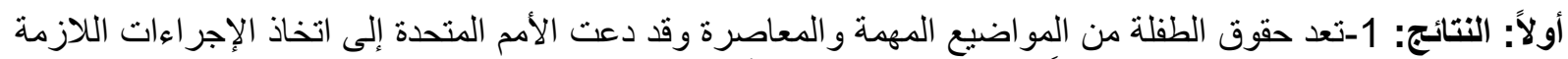

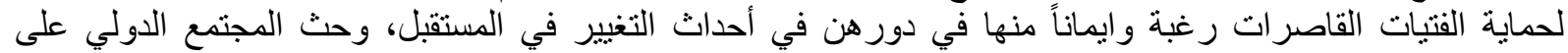
رعاية القاصر ات وتوفير الضمانات الكفيلة لحقوقهن.

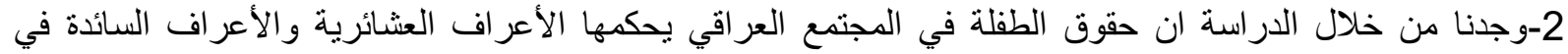

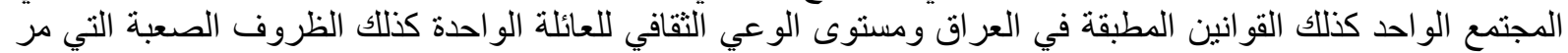

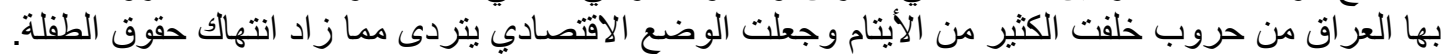

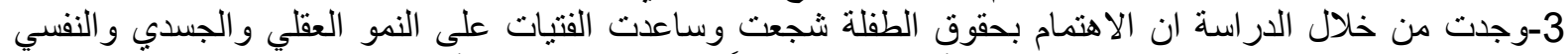

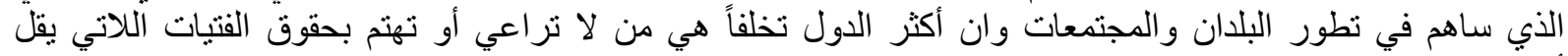

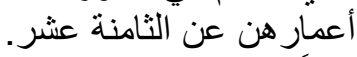

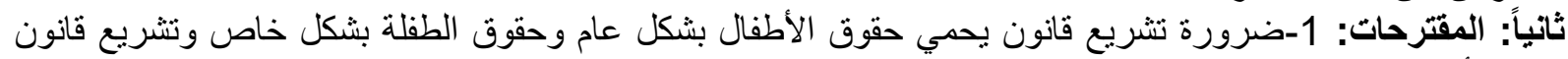

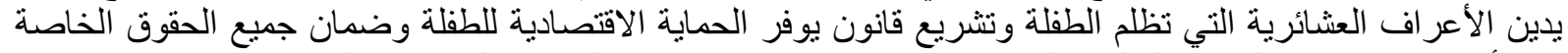

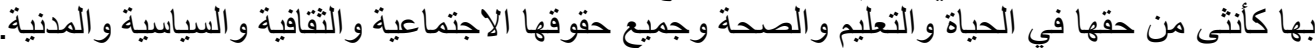

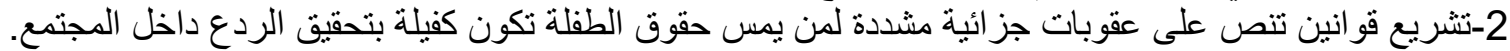

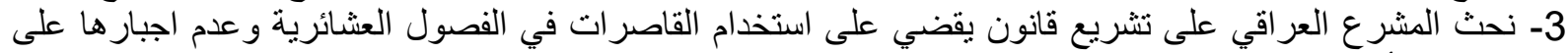

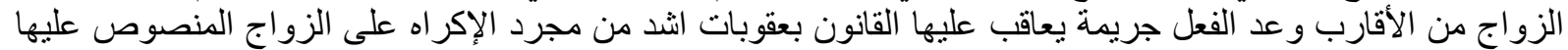
في قانون الأحو ال الثخصية العر اقي النافذ. 4-تشريع قانون يحمي حقوق الاطفال في اوقات النات النزاعات و الحروب.

المراجع

HUMAN RIGHTS WATCH: بلا ناريخ). تاريخ الاسترداد 23 1, 2021، من/Whinition of terms /http://www.hrw.org/report/2014/10/29

10 Elena Gaia. (9 October, 2015). Social Protction and Human Rights Enabling Aspirations, Realizing Rights: Social ن نارن iFebruary, 2021 Protection for Adolescent Girls: https://socialprotectionhumanrights.org/expertcom/enabling-aspirations-realizing-rights-social/protection-for-adolescent-girls

A Theory of Change من March, تاريخ الاسترداد 14 (Girls Not Brides. (9 July, 2014 on Child Marriage - Girls Not Brides: https://www.girlsnotbrides.org/articles/theory-change-child-marriage-girls-

/brides

Mackie, Gerry, Nkwi, Paul, Shakya, Holly Beniamino Cislaghi. (21 March, 2019). Global Public Health: تاريخ الاسترداد 22 2021, Taylor\&Francis online https://www.tandfonline.com/doi/full/10.1080/17441692.2019.1594331 Nutalia López Gril's Right : من من /https://www.humanium.org/en/girls-rights How China's One-Child Policy ناريخ الاسترداد 21 7), 2021) من/(NPR. (1 February, 2016 Led To Forced Abortions, 30 Million Bachelors: https://www.npr.org/2016/02/01/465124337/how-chinas-one-child-policyled-to-forced-abortions-30-million-bachelors 
Office The People's Movement for Human Rights Education (PDHRE) / NY A Dream to Come تاريخ الاسترداد 2021، من Human Rights \& the Girl-Child True:HUMAN RIGHTS AS A WAY OF LIFE: https://www.pdhre.org/rights/women_girl_child.html Chapter 12: Rights of the Girl Child . بلا تاريخ). Robin N. Haarr BCcampus Open نublishing: https://opentextbc.ca/womenintheworld/chapter/chapter-12-rights-of-the/girl-child

Theories \& Approaches International Girls Development, The Resource Center for january, تاريخ الاسترداد. (Adolescent Pregnancy Prevention (ReCAPP). (1995

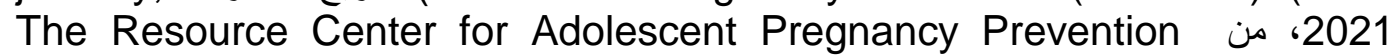

(ReCAPP):

http://recapp.etr.org/recapp/index.cfm?fuseaction=pages. TheoriesDetail\& PageID=343 About UN Woman . UN WOMAN https://www.unwomen.org/en/about-us/about-un-women A تاريخ الاسترداد 23 Anited Nation. (8 10, 2020). United Nations International Day of the Girl Child: https://www.un.org/en/observances/girlchild-day

March, تاريخ الاسترداد United Nations. (24 October, 1945). United Nations Charter https://www.un.org/en/about-us/un-charter/full-text 2021 United Nations. (10 December, 1948). Universal Declaration of Human Rights https://www.un.org/en/about-us/universal- من من February, 202120 الاسترداد 202 declaration-of-human-rights 10 United Nations. (8 October, 2020). International Day of the Girl Child International Day of the Girl Child: نارن 'January, 2021 https://www.un.org/en/observances/girl-child-day اسماعيل بن عمر بن كثير الدمشقي ابو فداء عماد الدين ابن كثير ـ (1420ه-1999). تفسير ابن كثير ـ (المحقق: سامي

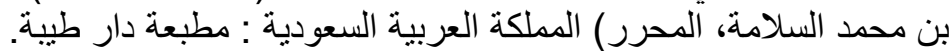

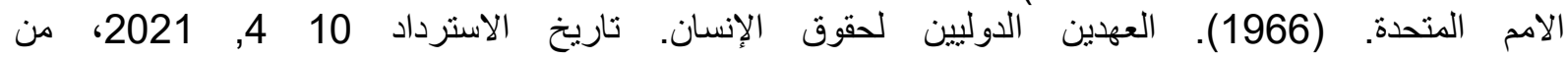
https://www.ohchr.org/Documents/Publications/CoreTreatiesar.pdf

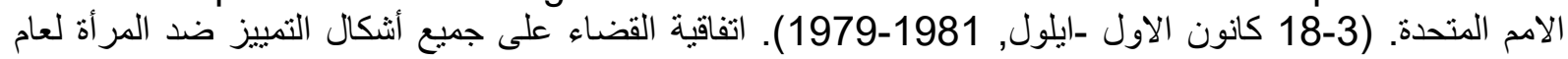
8EDAW 1979 (تاريخ https://www.ohchr.org/ar/professionalinterest/pages/cedaw.aspx

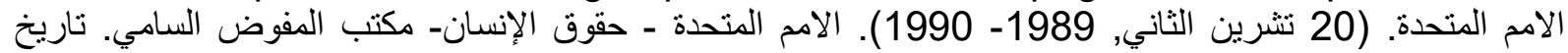

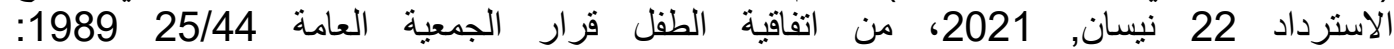
https://www.ohchr.org/ar/professionalinterest/pages/crc.aspx البرلمان العراقي ـ (كانون الثاني, 2006). البرلمان العراقي. تاريخ الاسترداد 13 ايار, 2021، من دستـور

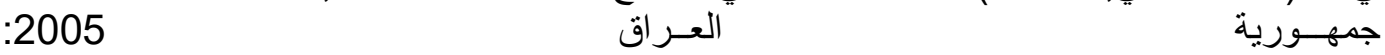
https://ar.parliament.iq/\%D8\%A7\%D9\%84\%D8\%AF\%D8\%B3\%D8\%AA\% $\mathrm{D} 9 \% 88 \% \mathrm{D} 8 \% \mathrm{~B} 1-$ 1\%D8\%A7\%D9\%84\%D8\%B9\%D8\%B1\%D8\%A7\%D9\%82\%D9\%8A الجمعية العامة للامم المتحدة. (10 كانون الاول, 1984). اتفاقية مناهضة التعذيب 46/39. نيويورك، الو لايات المتحدة

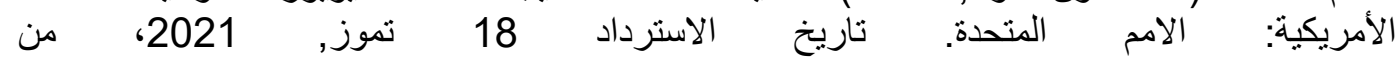
https://www.ohchr.org/ar/professionalinterest/pages/cat.aspx

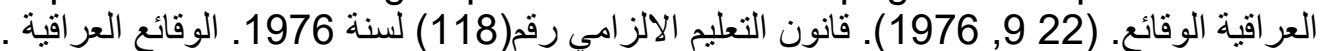
العر اقية وقائع. (12 12, 1917. 1971). قانون محو الامية العراقي ـ مجموعة القوانين والانظمة ، العدد 2075، صفحة .1017 


\section{العر اقية وقائع. (18 كانون الاول, 1979). قانون الحملة الوطنية لمحو الامية الثامل. غير نافذ.

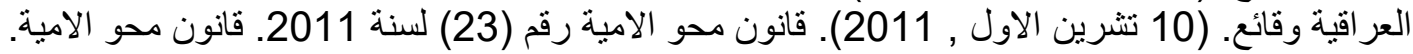

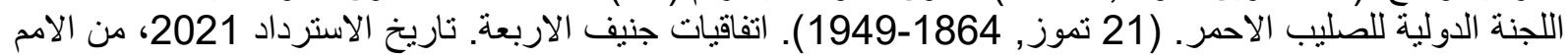

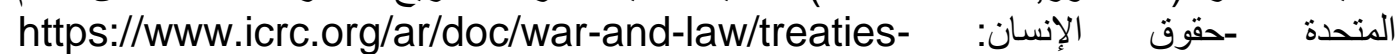

customary-law/geneva-conventions/overview-geneva-conventions.htm

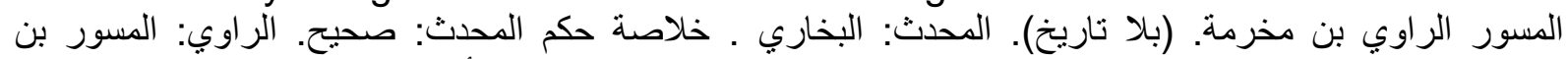

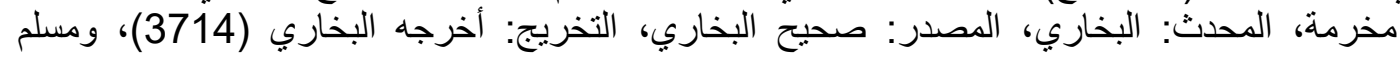
(2449)

المعاني لكل رسم. (بلا تاريخ). تاريخ الاسترداد 22 نيسان, 2021، من المعجم الجامع معجم عربي -عربي: /https://www.almaany.com/ar/dict/ar-ar/\%D8\%B7\%D9\%81\%D9\%84

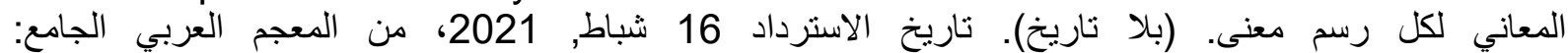
/https://www.almaany.com/ar/dict/ar-ar/\%D9\%85\%D9\%8A\%D8\%B2

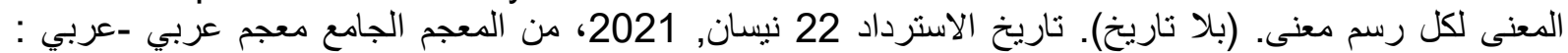
https://www.almaany.com/ar/dict/arlar/\%D8\%A7\%D9\%84\%D8\%AD\%D9\%82

المؤتمر العام لمنظمة الامم المتحدة للتربية والتعليم. (14--22 كانون الاول -ايار, -1962 1960). اتفاقية مكافحة

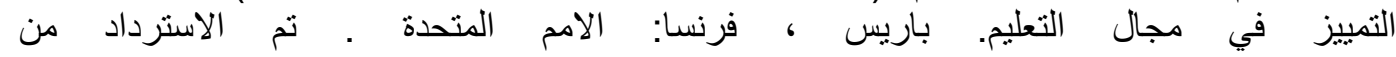
https://www.un.org/ar/events/motherlanguageday/pdf/DiscriminEducConv. pdf

المؤتمر العام لمنظمة العمل الدولية، و المؤتمر العام منظمة العمل الدولية ـ (26-1973 حزير العان, 1973). العمل الدولية بشأن الحد الأدنى لسن العمل رقم (138) لسنة 1973. تاريخ الاسترداد 1973 -1976، 1973 العنة

https://www.ohchr.org/AR/Professionallnterest/Pages/MinimumAge.aspx

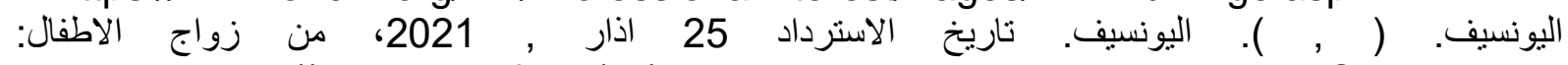
https://www.unicef.org/ar/\%D8\%B2\%D9\%88\%D8\%A7\%D8\%AC\%D8\%A7\%D9\%84\%D8\%A3\%D8\%B7\%D9\%81\%D8\%A7\%D9\%84/\%D8\% AD\%D9\%85\%D8\%A7\%D9\%8A\%D8\%A9\%D8\%A7\%D9\%84\%D8\%B7\%D9\%81\%D9\%84

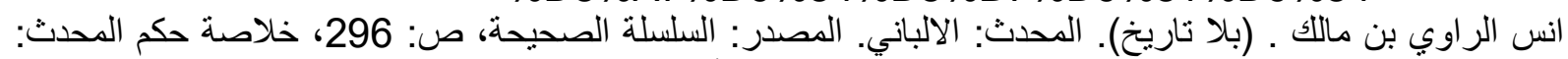

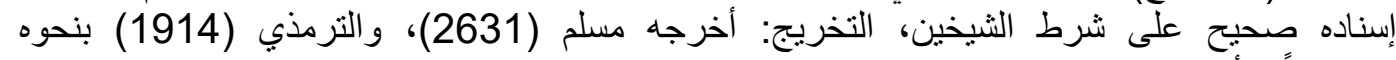

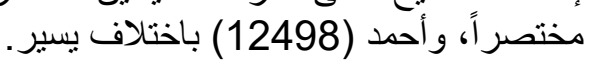

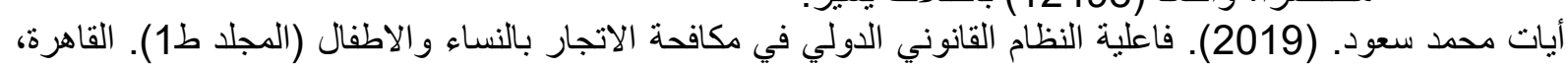

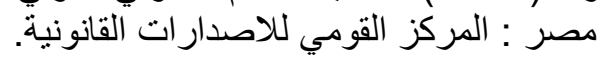
تقرير الامم المتحدة. (2020). جودة التعليح.

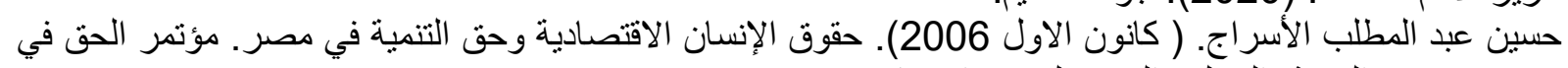

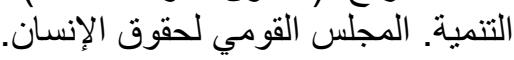

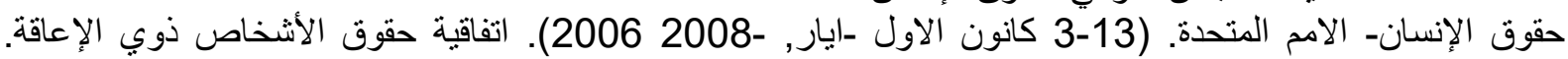

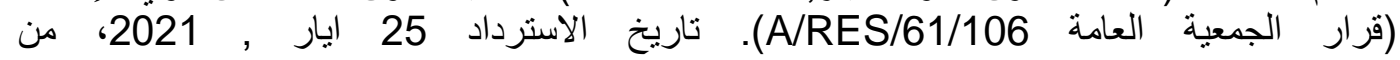
https://www.ohchr.org/ar/HRBodies/CRPD/Pages/ConventionRightsperson

sWithDisabilities.aspx

رضي الله عنها عائشة. (بلا تاريخ). حديث صحيح. المحدث: الالباني، المصدر : صحيح الترمذي ص2839.

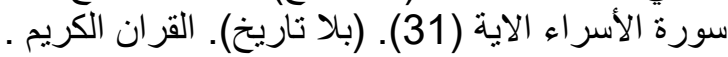

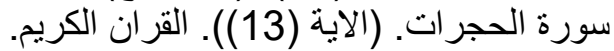

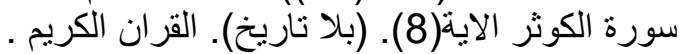

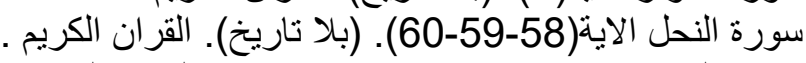

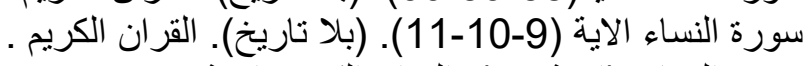

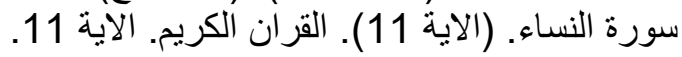

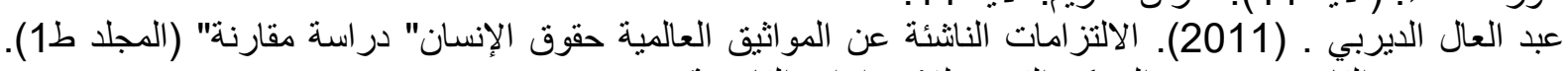
القاهرة، مصر : المركز القومي للاصدار النئ القات القانونية . 
عبد الله الراوي بن عباس ـ (بلا تاريخ). المحدث احمد شاكر ـ المصدر: مسند أحمد، ص: 294/3، خلاصة حكم

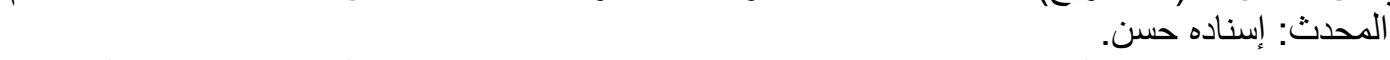

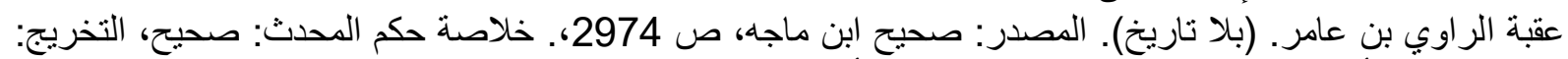

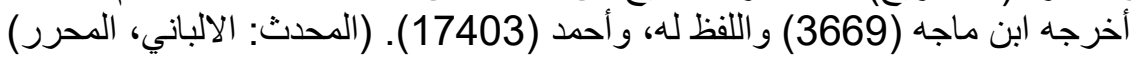

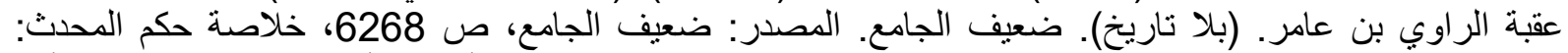

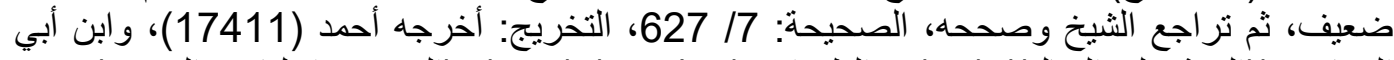

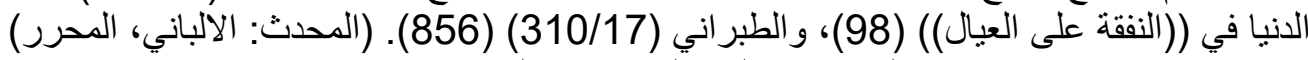

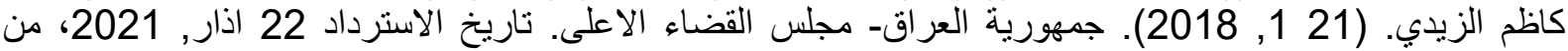

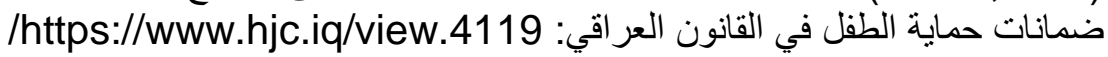

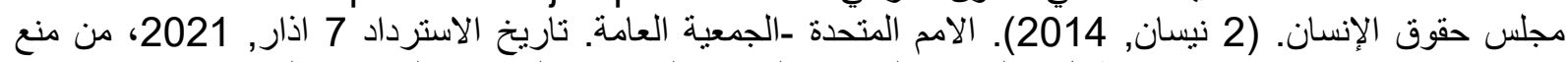

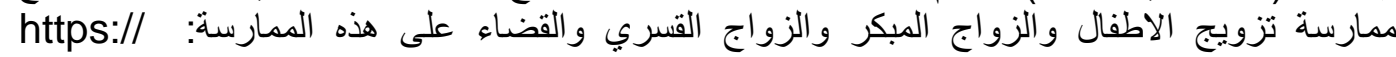
www.ohchr.org

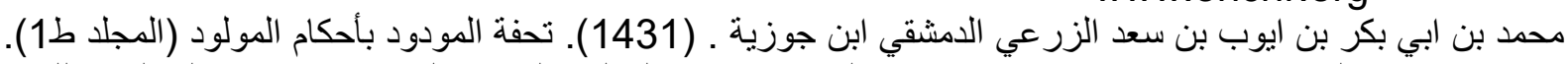

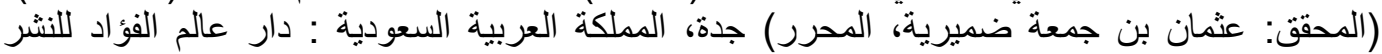
والتوزيع.

محمد عادل سكر ـ (2018). حق الطفل في الخصوصية في القانون الدولي. ، الجيزة، مصر : مركز الدراسات العربية. منظمة اليونسيف. (2018). اليونسيف لكل طفل. تاريخ الاسترداد 22 إيار , 2021 2018، من حماية الطفل: https://www.unicef.org/iraq/ar/\%D8\%AD\%D9\%85\%D8\%A7\%D9\%8A\%D8 $\%$ A9-

\%D8\%A7\%D9\%84\%D8\%B7\%D9\%81\%D9\%84/\%D9\%85\%D8\%A7\%D8\% B0\%D8\%A7-\%D9\%86\%D9\%81\%D8\%B9\%D9\%84 نبراس ظاهر الزيادي. (2018). القانون الدولي الخاص- أحكام الجنسية والموطن ومركز الاجانب. بيروت: دار السنهوري. يوسف حسن يوسف. (2013). حقوق المراة في القانون الدولي والثريعة الإسلامية (المجلد ط1). القاهرة، مصر : المركز القومي للاصدار ات القانونية. 